\title{
TLR-dependent $T$ cell activation in autoimmunity
}

\author{
Kingston H.G. Mills \\ Immunology Research Centre and School of Biochemistry and Immunology, \\ Trinity College Dublin, Ireland
}

\begin{abstract}
Autoimmune disease can develop as a result of a breakdown in immunological tolerance, leading to the activation of self-reactive $\mathrm{T}$ cells. There is an established link between infection and human autoimmune diseases. Furthermore, experimental autoimmune diseases can be induced by immunization with autoantigens that are administered together with complete Freund's adjuvant containing killed Mycobacteria tuberculosis, which in some cases can be replaced with individual pathogen-associated molecular patterns (PAMPs). Exogenous PAMPs and endogenous danger signals from necrotic cells bind to pathogen recognition receptors, including Toll-like receptors, and activate signaling pathways in innate immune cells and on $\mathrm{T}$ cells, leading to inflammatory cytokine production and $\mathrm{T}$ cell activation, and this is now considered to be a major factor in the development of autoimmunity.
\end{abstract}

\section{Introduction}

The discovery by Janeway and Mezhitov that innate immune cells sense pathogens through pathogen recognition receptors (PRRs), has revolutionized our understanding of the role of the innate immunity in infection and in driving $\mathrm{T}$ cell responses ${ }^{1}$. It has also significantly enhanced our understanding of the mechanisms of immune dysregulation leading to autoimmunity. Organspecific autoimmune diseases can develop through a combination of hereditary and environmental factors that lead to a failure to regulate adaptive immune responses to self antigens, in particular those mediated by IL-17-producing $\mathrm{T}$ helper cells $\left(\mathrm{T}_{\mathrm{H}} 17 \text { cells }\right)^{2}$. The 
mechanism is thought to involve a breakdown of immunological tolerance, mainly due to defective regulatory $\mathrm{T}\left(\mathrm{T}_{\mathrm{Reg}}\right)$ cell function, which leads to the uncontrolled generation of autoantigen-specific antibodies and pathogenic $\mathrm{T}$ cells that mediate tissue inflammation ${ }^{3}$.

Inflammatory $\mathrm{T}$ cells are induced by pathogen- or commensal- derived molecules, as well as by endogenous stress-induced self molecules. These microbe-associated molecular patterns (MAMPs) and damage-associated molecular patterns (DAMPs) [G] induce inflammatory T cells either indirectly through the induction of pro-inflammatory cytokine production by innate immune cells, or directly through their binding to PRRs on T cells. Evidence for this is provided by the described association between infections and autoimmune diseases (such as multiple sclerosis and rheumatoid arthritis), which develop following activation of self-reactive $\mathrm{B}$ and $\mathrm{T}$ cells, or between infections and chronic inflammatory diseases (such as Crohn's disease) which result from uncontrolled innate and adaptive immune responses to normal constituents of the gut microflora.

There are several families of PPRs: Toll-like receptors (TLRs) sense conserved molecules from bacteria, virus and parasites; the cytosolic nucleotide binding oligomerization domain (NOD)-like receptors (NLRs) sense bacterial products; c-type lectin receptors (CLRs) bind $\beta$-glucans; and RIG-1-like receptors (RLRs) bind nucleic acids ${ }^{4-5}$. There have been a number of exciting recent discoveries that have linked the activation of PRRs with autoimmune diseases, especially around the capacity of exogenous and endogenous ligands to promote innate inflammatory responses that drive the induction of autoreactive $\mathrm{T}$ cells, in particular IL-17producing $\mathrm{T}_{\mathrm{H}} 17$ cells and $\gamma \delta \mathrm{T}_{\text {cells }}{ }^{6-11}$. Coupled with the discoveries around the pathogenic role of these IL-17-producing $\mathrm{T}$ cells in autoimmunity, this has significantly advanced our understanding of the disease process in many autoimmune disorders. TLRs are a key family of PRRs involved in driving autoimmune inflammation, therefore, inhibitors of TLR binding or signaling are now considered to have great potential as therapeutics for autoimmune and other inflammatory diseases.

This Review article discusses the role of TLRs in organ-specific autoimmune diseases in the context of direct and indirect (through innate immune cell-derived cytokines) activation of auto-reactive $\mathrm{T}$ cells either directly or via innate immune cells. In addition, it explores new immunotherapeutic approaches based on inhibiting TLR-induced immune activation. 
PAMPs shape innate and adaptive immune responses PRRs are expressed by a variety of cell types, especially cells of the innate immune system, such as dendritic cells (DC) and macrophages, where they sense danger or damage signals. The PRR ligands include pathogenassociated molecular patterns (PAMPs) [G] - conserved microbial structures, such as lipopolysaccharide (LPS), flagellin, viral and bacterial nucleic acids - but also endogenous danger signals from dead and dying cells, called DAMPs, such amyloid- $\beta$ and saturated fatty acids (BOX 1). The primary function of PRRs is to mediate innate immune responses to pathogens and tumors, but they also have a role in sterile inflammation $[\mathbf{G}]$ and have been linked with autoimmune and chronic inflammatory diseases ${ }^{1,4}$.

Innate immune cells, especially DCs, direct adaptive immunity, not only by acting as antigen presenting cells (APCs) for naïve $\mathrm{T}$ cells, but also by providing the cytokine stimulus (the third signal) for $\mathrm{T}$ cell activation ${ }^{1-2}$. Binding of agonists to TLRs promotes DC maturation and production of $\mathrm{T}$ cell-promoting cytokines ${ }^{1}$, using distinct signaling pathways (FIG. 1). Activation of NF- $\mathrm{KB}$ results in production of the pro-inflammatory cytokines, including tumour necrosis factor (TNF), interleukin-6 (IL-6), pro-IL-1 $\beta$ and pro-IL-18 $8^{4-5}$. Activation of the interferon regulatory factor (IRF) pathways mediate IL-12p35 and type I interferon (IFN) production, whereas active extracellular signal-regulated kinase (ERK) and p38 MAP kinases are required for IL-23p19 and IL-10 production respectively ${ }^{5,12-13}$ (FIG. 1). TLR agonists have potent immunomodulatory activity and can promote adaptive immune responses to coadministered antigens and consequently have been exploited as adjuvants in infectious disease and cancer vaccines and as tumor immunotherapeutics ${ }^{14-15}$. Conversely, because of their ability to activate innate immunity and inflammation, molecules that antagonize TLR ligand binding or inhibit TLR signaling pathways are being developed as therapies against autoimmune and other inflammatory diseases ${ }^{5}$.

Targeting innate cytokines that promote pathogenic $\mathrm{T}$ cell responses has become a major focus in drug development against autoimmune diseases (FIG. 2). Whereas much of the initial focus was on IL-12, which is the key driver of pathogenic $T_{H} 1$ cells, the discovery of $T_{H} 17$ cells and their role in autoimmunity (BOX 2) has shifted the emphasis to the innate regulatory cytokines IL-6, IL-23 and IL-1, which promote the development of $\mathrm{T}_{\mathrm{H}} 17$ cells. It is now recognized that IL- 6 and TGF $\beta$ promote differentiation of murine $\mathrm{T}_{\mathrm{H}} 17$ cells from naïve $\mathrm{CD} 4^{+} \mathrm{T}$ cells $^{16-18}$ and that IL-23 and IL-1 $\beta$ or IL-18 (which are produced via activation of caspase-1 and 
the NLRP3 inflammasome [G] in TLR-primed DCs ${ }^{8}$ ) promote expansion and IL-17 production by memory $\mathrm{T}_{\mathrm{H}} 17$ cells ${ }^{19-20}$ (FIG 3). Moreover, it has been suggested that IL-23 can also induce differentiation of $\mathrm{T}_{\mathrm{H}} 17$ cells $^{21-22}$.

As well as having an indirect role in promoting IL-17 production by T cells, there is increasing evidence that PRR-triggered innate immune cells can act as a direct source of IL-17. $\gamma \delta \mathrm{T}$ cells ${ }^{6,23}$, natural killer $\mathrm{T}$ (NKT) cells ${ }^{24}$ and lymphoid tissue inducer-like (LTi) [G] cells ${ }^{25}$ have all been shown to be important sources of IL-17 and associated cytokines. We have demonstrated that IL- $1 \alpha$ or IL- $1 \beta$ can synergize with IL-23 to promote IL-17 secretion from $\gamma \delta$ T cells without $\mathrm{T}$ cell receptor engagement ${ }^{6,19} \cdot \gamma \delta$ T cells secrete IL-17, IL-21 and IL-22 and act in an amplification loop to expand $\mathrm{T}_{\mathrm{H}} 17$ cells $^{6}$. A high frequency of IL-17-producing $\gamma \delta \mathrm{T}$ cells are found in the CNS of mice with experimental autoimmune encephalitis (EAE), where they function with $\mathrm{T}_{\mathrm{H}} 17$ cells to mediate autoimmune inflammation ${ }^{6,26}$.

Although much of the focus on TLRs has center around their role in sensing and responding to infection by the innate immune system, it is now clear that TLRs agonists also have a crucial role in adaptive immunity. Indeed activation of DC and other innate immune cells through PRRs appears to be a critical step in the induction of $\mathrm{T}$ cell responses to pathogens, but also in the early inflammatory responses that lead to the development of autoreactive B and $\mathrm{T}$ cells that mediate many autoimmune diseases.

\section{The link between PAMPs and autoimmunity}

Expression of PRRs has been found in tissues of patients with organ-specific autoimmunity. Furthermore a polymorphism in TLR2 is associated with type 1 diabetes ${ }^{27}$ and polymorphisms in TLR4 and TLR9 have been described in patients with Crohn's disease ${ }^{28}$. Mutations in NOD2 have been strongly associated with Crohn's disease, and the synergy between NOD2 and TLR9 activation of inflammatory cytokine production by peripheral blood mononuclear cells is lost in cells from patients with the NOD2 mutation ${ }^{29}$. Moreover, the presence of PAMPs in tissues following infection has been associated with autoimmunity. These observations provide indirect evidence that PAMPs may promote autoimmune and chronic inflammatory diseases.

Infections precipitate autoimmune diseases. There is a well established link between infection and autoimmune diseases both in clinical settings and in animal models. This link has been 
attributed to either molecular mimicry between pathogen-derived antigens and self antigens or non-specific activation of innate immunity leading to a breakdown in immunological tolerance and the development of self antigen-specific $\mathrm{T}$ cell- and antibody-responses.

Transgenic mice expressing a $\mathrm{T}$ cell receptor (TCR) specific for a myelin-derived peptide develop spontaneous EAE when housed in conventional, but not specific pathogen free conditions $^{30}$. This suggests that infection may precipitate autoimmunity in mice. Several studies in multiple sclerosis patients have suggested that disease may be triggered or exacerbated by infections with Chlamydia pneumonia, human herpes virus 6 or Epstein-Barr virus (EBV). The strongest evidence comes from studies on EBV, as viral latent protein has been found in the brain of patients with multiple sclerosis ${ }^{31}$. In patients with relapsing remitting multiple sclerosis, there is an association between upper respiratory tract infections and relapse ${ }^{32}$. It has also been reported that systemic infections may trigger relapse in multiple sclerosis by bystander enhancement of myelin-specific $\mathrm{T}$ cell responses ${ }^{33}$.

Parvovirus B19 is considered to be one triggering factor for rheumatoid arthritis; the virus was detected by PCR in synovial biopsies of $75 \%$ of patients with rheumatoid arthritis compared with $17 \%$ of patients with osteoarthritis and other arthritides ${ }^{34}$. Furthermore, EBV DNA and RNA were detected in $34 \%$ of patients with rheumatoid arthritis compared with $10 \%$ of healthy individuals ${ }^{35}$.

Commensal microorganisms may also be involved in the development of autoimmune diseases, as suggested by the finding that some species of gut microbiota promote the pathogenesis of inflammatory bowel disease, especially Crohn's disease ${ }^{36}$. Commensal microbes, in particular segmented filamentous bacteria have been shown to promote the induction of $T_{H} 17$ cells $^{9}$ and as well contributing to intestinal inflammation, these $\mathrm{T}_{\mathrm{H}} 17$ cells can also drive autoimmune arthritis ${ }^{37}$. It has also been reported that commensal bacteria-derived ATP promotes IL-6, TGF $\beta$ and IL-23 production by DC, leading to local activation of naturally occurring and pathogenic $\mathrm{T}_{\mathrm{H}} 17$ cells $^{38}$. However, this was independent of TLR signaling. Conversely, studies in a $T$ cell transfer model of colitis showed that commensal bacteria promote $T_{H} 1$ and $T_{H} 17$ responses by MYD88-dependant activation of innate immune responses ${ }^{39}$. Although IL-6 was implicated, a role for commensal-induced IL-1 in promoting $\mathrm{T}_{\mathrm{H}} 17$ responses has not been ruled out. These studies point to a role for pathogens and commensal bacteria in promoting or exacerbating autoimmune diseases. 
PAMPS may exacerbate autoimmunity. In addition to initiating autoimmune and chronic inflammatory diseases, PAMPs may exacerbate these diseases. Infection with Streptococcus pneumonia 7 days after induction of EAE exacerbates autoimmunity in wildtype but not $T l r 2^{-/-}$ mice $^{40}$. This suggests that pathogens may exacerbate autoimmune diseases via activation of TLRs. Furthermore, PAMPs are present in diseased tissues of patients with autoimmunity. For example, peptidoglycans, which include NLR and TLR2 ligands, has been found in synovial tissue macrophages and DCs isolated from patients with rheumatoid arthritis ${ }^{41}$, in the bowel wall of patients with Crohn's disease ${ }^{42}$, in the brain of primates with $\mathrm{EAE}^{43}$ and in macrophages and DCs in the brain of patients with multiple sclerosis ${ }^{44}$. Interestingly, the expression of some TLRs (such as TLR2 and TLR3) is enhanced in astrocytes and oligodendrocytes from multiple sclerosis patients, suggesting that increased TLR signaling may occur during ongoing autoimmunity ${ }^{45}$. This in turn may exacerbate autoimmunity. Indeed, treatment of cancer patients with the TLR7/8 agonist imiquimod exacerbates psoriasis ${ }^{46}$.

Some infections suppress autoimmunity. In addition to driving autoimmunity, certain infections have also been associated with suppression of autoimmune diseases. Epidemiological data has shown that incidence of multiple sclerosis and type 1 diabetes is increasing in developed countries, and this correlates with a decrease in the number of infections ${ }^{47}$. Conversely, a higher incidence of infection with helminth parasites in rural parts of developing countries is associated with a lower incidence of allergy and autoimmune diseases ${ }^{48}$. The so-called 'hygiene hypothesis' suggests that anti-inflammatory cytokines or $\mathrm{T}_{\text {Reg }}$ cells induced by such infections exert bystander suppression on the immune responses that mediate allergy and autoimmunity ${ }^{48-49}$. This hypothesis is supported by mouse studies showing that helminth infections can suppress autoimmunity through bystander suppression of autoantigen-specific $\mathrm{T}_{\mathrm{H}} 17$ cells, through induction of anti-inflammatory cytokines and $\mathrm{T}_{\text {Reg }}$ cells ${ }^{50}$. It has also been shown that infection of germ-free mice with a single human commensal Bacteroides fragilis protected against EAE through $\mathrm{T}_{\text {Reg }}$ cell induction ${ }^{51}$. So, although much of the evidence points to a role for pathogens and commensal bacteria, especially those that induce potent $\mathrm{T}_{\mathrm{H}} 17$ responses, in promoting autoimmune inflammation, chronic infections, especially with parasites that are sustained and dominated by $\mathrm{T}_{\text {Reg }}$ cells, may have the opposing effect of attenuating autoimmunity. 


\section{Role of DAMPs in autoimmuneity}

While pathogens and their products have been implicated in precipitating autoimmune diseases in humans and can induce experimental autoimmunity in animal models, there is also evidence that DAMPs or alarmins [G] released from dead and dying cells can stimulate innate immune responses leading to autoimmunity (FIG. 4). Polly Matzinger first suggested that, as well as responding to PAMPs, APCs can also respond to danger or alarm from endogenous molecules produced by distressed tissues, called DAMPs ${ }^{52}$. The term alarmin was coined by Joost Openheim $^{53}$ to describe a group of mediators released by necrotic cells in response to infection or injury that interact with PRRs and activate innate immune cells, including DC and thereby enhance $\mathrm{T}$ cell responses. It has been suggested that alarmins are members of a larger family of DAMPs that also includes PAMPs ${ }^{54}$.

Human mobility group box protein 1 (HMGB1) is considered to be a DAMP capable of activating innate immune responses. Although there are reports that it may bind to TLR4 and other TLRs, many of the early studies on HMGB1 and other putative DAMPs were compromised by contamination with PAMPs, especially LPS. However, it has recently been reported that HMGB1 can stimulate innate immune responses by acting as a universal sentinel for nucleic acids ${ }^{55}$. HMGB1 binds to most or all nucleic acids facilitating their interaction with nucleic acid-sensing TLRs (TLR3, TLR7 and TLR9) and cytosolic nucleic acid binding sensors (RIG-1, MDA5, DAI, AIM2) on innate immune cells. Interestingly, HMGBI concentrations are elevated in the blood of patients with SLE, compared with healthy controls and there was a positive correlation between HMGB1 concentrations and disease activity ${ }^{56}$. This provides indirect evidence that this endogenous DAMP may be involved in the pathogenesis of human autoimmune diseases.

In a murine model of neutrophilic inflammation, Chen et al found that intraperitoneal injection of dying cells into mice induced recruitment of neutrophils, which was not associated with HMGB1, but was mediated through MYD88 and IL-1, rather than TLR signals ${ }^{57}$. The neutrophil recruitment and the production of the hepatic enzyme alanine aminotransferase (ALT) that were observed in wild-type mice were absent in IL-1RI ${ }^{-1-}$ mice but not in mice defective for a range of TLRs, IL-18R, caspase-1. Moreover, the inflammatory response was blocked by IL-1 $\alpha$ specific blocking antibody, suggesting that IL-1 $\alpha$ is key alarmin driving sterile inflammation. As 
IL-1 $\alpha$ promotes IL-17 production by $\mathrm{T}$ cells ${ }^{19}$, it may be an important endogenous activator of pathogenic $\mathrm{T}$ cells in autoimmune diseases.

Another alarmin, 15-ahydroxicholesterene (15-HC), is a derivative of cholesterol and activates microglia via TLR2 and polyADP-ribose polymerase 1 (PARP1). 15-HC is elevated in the serum of patients during the progressive phase of multiple sclerosis and in mice with secondary progressive $\mathrm{EAE}^{58}$. TLR2-specific antibody inhibited activation of PARP1 by $15-\mathrm{HC}$ and attenuated the progression of $\mathrm{EAE}^{58}$.

Furthermore, human synovial membrane cultures from patients with rheumatoid arthritis were found to express TLR2 and TLR4 and to release endogenous TLR ligands which may contribute to destructive inflammation in the joints of these patients ${ }^{59}$. Finally, it has recently been shown that heterogeneous nuclear ribonucleoprotein (hbRNP), an RNA and DNA-binding protein that is a target of most nuclear antigen-specific $\mathrm{T}$ and $\mathrm{B}$ cells in systemic autoimmune diseases but also in human rheumatoid arthritis and in pristine-induced arthritis in rats, triggers TLR7- and TLR9- mediated activation of arthritogenic APCs, which activate pathogenic T cells ${ }^{60}$.

Although much of the early studies on DAMPs may be compromised by contamination issues, the more recent studies with knockout mice and molecular defined alarmins suggest that they can promote innate and as a consequence adaptive immune responses that mediate autoimmunity. However, it is still to clear whether this sterile inflammation is sufficient to kick start autoreactive $\mathrm{T}$ cell responses, or whether it amplifies responses induced by PAMPs.

\section{TLRs in animal models of autoimmunity}

Studies using TLR-defective mice, TLR-specific blocking antibodies, inhibitors of TLR signaling, or TLR agonists in animal models of autoimmune diseases have provided insight into the role of TLR activation in the initiation or exacerbation of autoimmunity (Tables 1 and 2).

The role of TLRs in EAE. Actively-induced EAE involves immunization of mice with myelinderived peptides in complete Freund's adjuvant (CFA). M. tuberculosis in CFA contains PAMPS that activate innate immune responses, which in turn promote the pathogenic auto-reactive $\mathrm{T}$ cell responses. Reports by Prinz et $\mathrm{al}^{10}$ and Marta et $\mathrm{al}^{61}$ showed that mice deficient in MYD88, an adapter protein for IL-1 receptor and all TLRs except from TLR3, are resistant to EAE. This was 
associated with reduced IL-6 and IL-23 production by DCs and reduced IL-17 and IFN $\gamma$ production by $\mathrm{T}_{\text {cells }}{ }^{10}$ (Table 1). This suggests that innate immune responses, initiated through TLRs or IL-1R signaling, are required for the induction of experimental autoimmunity.

Mice with a lymphoid cell-specific TLR2 deficiency were less susceptible to EAE and had reduced $\mathrm{T}_{\mathrm{H}} 17$ responses ${ }^{62}$ than wild type controls. The reduction in disease severity and IL17 production was even more dramatic when EAE was induced by adoptive transfer of TLR2deficient $\mathrm{T}$ cells. This suggests that TLR2 signalling in $\mathrm{T}$ cells may be important for the induction of EAE. In addition, TLR2 may be involved in the activation of CNS-infiltrating macrophages, microglia or astrocytes during development of $\mathrm{EAE}^{58}$.

A study by Prinz et al. showed that disease severity was reduced in TLR9-defecient mice, though not as dramatically as in $M y d 88^{-/-}$mice $^{10}$. Moreover, disease onset was delayed in $\operatorname{Tr} 9^{-/-}$ mice following transfer of MOG-specific $\mathrm{T}$ cells from wild-type mice ${ }^{10}$, implicating a role for TLR9-induced innate immune activation in promoting the pathogenic function of activated autoreactive T cells. Indeed APC activation through TLR9 could break tolerance and facilitate the induction of $\mathrm{EAE}^{63}$. Immunization of mice with proteolipid protein (PLP) in incomplete Freund's adjuvant (IFA) induces tolerance due to lack of danger signals provided by the $M$. tuberculosis of the CFA. However, transferred lymph node cells from these tolerized mice induced EAE following stimulation with $\mathrm{CpG}^{63}$, providing further evidence of a proinflammatory role for TLR9 activation. This is consistent with the demonstration that TLR9 activation may circumvent tolerance and promote intestinal inflammation by suppression of $\mathrm{T}_{\text {Reg }}$ cell conversion ${ }^{64}$.

Interestingly, the study by Marta et al. showed that mice defective in either TLR9 or TLR4 had enhanced IL-6, IL-23 and IL-17 expression and developed severe EAE ${ }^{61}$, suggesting a protective role for these TLRs in this autoimmune disease. In this study mice were immunized once with MOG peptide, whereas in the study by Prinz and colleagues mice were immunized twice with myelin protein, and this may have obscured the regulatory role of TLR ${ }^{61}$.

Finally, it has been reported that parenteral injection of poly I:C, a TLR3 ligand, suppressed relapsing-remitting EAE and this was associated with IFN- $\beta$ production ${ }^{65}$. Collectively these findings indicate that TLR and IL-1 signalling is crucial for the induction of EAE, but that there may be redundancy between certain TLRs. Moreover, certain TLRs may be pro-inflammatory (TLR2 and TLR9), whereas others (TLR3 and TLR9) may also have a 
regulatory role in EAE, depending on the different stages of disease. When compared with knockout mouse studies, studies with TLR-specific antibodies or inhibitors, which can be used to block TLR signalling at different stages of disease, may give a clearer picture of the potential of the role of individual TLR pathways in EAE and other autoimmune diseases.

The role of TLRs in arthritis. In most mouse models, arthritis is induced following activation of inflammatory responses by killed bacteria or their products and there is good evidence that this involves activation of PRRs. In the mouse model of collagen-induced arthritis (CIA), which is induced by immunization with collagen and CFA, M. tuberculosis in CFA provides a source of PAMPs. Staphylococcus epidermidis-derived peptidoglycans (which includes TLR2 and NLR agonists) was also shown to induce acute arthritis in mice ${ }^{66}$. Moreover, zymosan, a polysaccharide from the cell wall of Saccharomyces cerevisiae, which binds TLR2 and the CLR dectin-1, has been used to induce experimental arthritis in mice. Zymosan-induced arthritis was found to be dependent on TLR2 activation, as disease was significantly attenuated in $T l r 2^{-/-}$mice, but not by treatment with lamarin which blocks the dectin-1 receptor ${ }^{67}$. In addition, injection of immune stimulatory DNA sequences (ISS-ODN) into the joints of rats promoted the development of adjuvant arthritis ${ }^{68}$. This suggests that activation of TLR9 may also precipitate the innate immune responses that drive inflammation in the joint

Spontaneous $\mathrm{T}$ cell-mediated arthritis in IL-1 $\mathrm{Ra}^{-/-}$mice was dependant on TLR4 activation by microbial flora; germ-free mice or $\mathrm{Tlr}^{-/-} \mathrm{Ill} \mathrm{ra}^{-/-}$double knockout mice did not develop arthritis ${ }^{11}$. Furthermore, a TLR4 antagonist, LPS from Bartonella quintana, inhibited IL$1 \beta$ in the joint and attenuated arthritis in CIA and $I l 1 r a^{-/-}$arthritis models ${ }^{69}$. By contrast, Tlr2 ${ }^{-/-}$

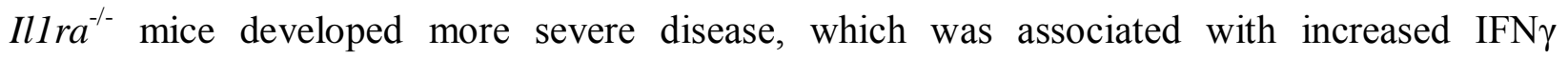
production by $\mathrm{T}$ cells and reduced $\mathrm{T}_{\mathrm{Reg}}$ cell function ${ }^{11}$, as direct TLR2 activation can induce expansion but transiently disrupt the function of $\mathrm{T}_{\text {Reg }}$ cells ${ }^{70}$. Thus microbiota may promote arthritis in Ill $\mathrm{ra}^{-/-}$mice by augmenting IFN $\gamma$ and suppressing $\mathrm{T}_{\text {Reg }}$ cell function via TLR2. So, unlike its role in EAE, where TLR2 signalling appears to drive inflammatory pathology, TLR2 may both promote and inhibit inflammatory $\mathrm{T}$ cell responses in mouse models of arthritis. However, there is more consistent evidence, from studies with the TLR4 antagonist as well as TLR4-deficient mice, that targeting TLR4 has potential in the treatment of arthritis. 
Other autoimmune diseases. Further studies with mouse models of autoimmunity reveal that the contribution of TLR signaling to the initiation of autoreactive $\mathrm{T}$ cell responses depends on the disease type and experimental conditions. For example, $M y d 88^{-/-}$mice are resistant to experimental autoimmune uveitis (EAU) and exhibit significantly reduced autoantigen-specific $\mathrm{T}_{\mathrm{H}} 1$ responses ${ }^{71}$, whereas $T l r 2^{-/-}, T l r 4^{-/-}$, and $T l r 9^{-/-}$mice develop normal $\mathrm{T}$ cell responses and are susceptible to EAU. By contrast, the development of type 1 diabetes in NOD mice is markedly reduced in the absence of TLR2 but not TLR $4^{72}$, and it appears that APCs sense apoptotic $\beta$ cell death through TLR2 and thereby promotes diabetogenic T cells.

Moreover, TLR2 and TLR9 were shown to have distinct pathogenic roles in a murine model of anti-neutophil cytoplasmic antibody-associated vasculitis (AAV), a multisystem autoimmune disease where neutrophil myeloperoxidase (MPO) is targeted by autoantibodies ${ }^{73}$. Immunization with MPO in the presence of the TLR2 agonist Pam3Cys enhanced vasculitis by promoting $\mathrm{T}_{\mathrm{H}}$ 17-dominated responses and neutrophil recruitment, whereas immunization with MPO and the TLR9 agonist CpG selectively promoted $\mathrm{T}_{\mathrm{H}} 1$ responses and macrophage activation $^{73}$. Finally, topical application of the TLR7/TLR8 agonist imiquimod in mice induces skin lesions in mice resembling psoriasis; this was associated with epidermal expression of IL-23 and IL-17 and enhanced $\mathrm{T}_{\mathrm{H}} 17$ cells in the spleen ${ }^{74}$.

Taken together, the studies in mouse models suggest that TLR agonists may trigger autoimmunity, with the most definitive phenotype seen in $M y d 88^{-/-}$mice. However, this adapter protein is also used for IL-1 signaling, so it cannot be inferred that the protective effect of MYD88 deficiency is solely due to a loss of TLR-mediated inflammation. Studies in mice lacking a single TLR have revealed less dramatic defects in induction of experimental autoimmunity in a number of models, with perhaps the best evidence supporting a role for TLR2 in EAE and TID, TLR4 in arthritis. Conversely there is evidence for a protective role for TLR3 in EAE. Finally, there are reports of protective as well as pathogenic roles for TLR9 in EAE and TLR2 in arthritis and further study is required to define the potential of these TLRs as targets in multiple sclerosis and rheumatoid arthritis.

\section{Indirect modulation of autoimmune $T$ cell responses by TLRs}

There is growing evidence that activation of PPRs on innate immune by pathogens or PAMPs cells can lead to a breakdown in self tolerance and bystander activation of autoreactive $\mathrm{T}_{\mathrm{H}} 1$ or $\mathrm{T}_{\mathrm{H}} 17$ cells. This supports the link between infection and autoimmunity. 
Activation of pathogenic $T$ cells. There is evidence that PAMP-induced secretion of proinflammatory cytokines from monocytes and DCs promotes the induction and expansion of $\mathrm{T}_{\mathrm{H}} 17$ cells $^{7,75-76}$ (FIG. 3). For example, human monocytes stimulated with LPS, zymosan, flagellin or lipoteichoic acid promote IL-17 production by anti-CD3 activated human CD4 $4^{+}$cells ${ }^{75}$. The TLR-induced signal was not identified, and addition of IL- 6 or TGF $\beta$ inhibited IL-17 production in this setting. Furthermore, hyphae of Candida albicans selectively promoted $\mathrm{T}_{\mathrm{H}} 17$ cell induction by inducing IL-23 but not IL-12 production from human monocytes and DCs ${ }^{77}$.

TLR3, TLR4 and TLR9 ligands induce MYD88-dependent production of cytokines from DCs, which promotes the differentiation of $\mathrm{T}_{\mathrm{H}} 17$ cells $^{18}$. Moreover, the TLR4 ligand LPS promotes IL-17 production by murine antigen-specific memory $\mathrm{T}$ cells through the induction of IL-1 and IL-23 production by DCs ${ }^{76}$. Finally, TLR2 agonists have been shown to promote the differentiation of murine $\mathrm{T}_{\mathrm{H}} 17$ cells in vitro ${ }^{62}$.

$\mathrm{T}_{\mathrm{H}} 17$ cells can also be induced independent of TLR and NLR activation, through activation of dectin- 1 with the $\beta$-glucan curdlan, which promotes IL-6, TNF and IL-23 production by $\mathrm{DCs}^{78}$. Similarly, bacterial derived ligands of NOD-2, such as muramyl dipeptide (MDP), have been shown to drive IL-17 production by human memory T cells by stimulating IL1 and IL-23 production by DCs ${ }^{7}$. Finally, it has been reported that commensal microbiota can promote differentiation of $\mathrm{T}_{\mathrm{H}} 17$ cells in the lamina propria of mice deficient in MYD88 and TLR3, suggesting that TLR and IL-1R signaling are not essential for induction of $T_{H} 17$ cells in the gut $^{79}$.

$T$ cell-mediated autoimmunity. The induction of experimental autoimmune disease in animal models, such as EAE, EAU and CIA, very often involves immunization with autoantigen in the presence of CFA. The killed Mycobacterium tuberculosis in CFA promotes innate inflammatory cytokines that direct the induction of $\mathrm{T}_{\mathrm{H}} 1$ and $\mathrm{T}_{\mathrm{H}} 17$ cells. $M$. tuberculosis has been shown to activate the NLRP3 inflammasome promoting IL-1 $\beta$ and IL-18 production $^{8}$, and to activate TLRs leading to IL- 6 and IL-23, which collectively drive the induction of $T_{H} 17$ and $T_{H} 1$ cells.

There have been several attempts to substitute M. tuberculosis with purified PAMPs (Table 2). Unlike PLP in CFA, which induced potent EAE, active immunization with PLP in IFA containing $\mathrm{CpG}$ failed to induce EAE, although mild disease was induced following the transfer 
of T cells from mice immunized with PLP in IFA with CpG to naïve recipients ${ }^{80}$. This effect was attributed to the fact that $M$. tuberculosis is a more potent adjuvant than $\mathrm{CpG}$ for induction of $\mathrm{T}_{\mathrm{H}} 17$ responses. By contrast, immunization of B10.S mice that express a transgenic TCR specific for PLP $139-151$ with IFA and CpG induced EAE in $73 \%$ mice compared with $33 \%$ that developed spontaneous disease ${ }^{81}$. The study demonstrated that activation of APCs via TLR9 can break tolerance and promotes the activation of self-reactive T cells. Interestingly, LPS was unable to break tolerance in this model.

In has been demonstrated that immunization of mice with MOG in IFA supplemented with zymosan can induce but not sustain EAE. Disease induction was associated with the generation of MOG-specific $\mathrm{T}_{\mathrm{H}} 17$ cells, and transient induction of IL-23 by DC ${ }^{82}$. Hansen et al. also reported that immunization with MOG in IFA supplemented with high dose zymosan or LPS, but not the TLR3 agonist poly I:C, could induce EAE ${ }^{83}$. The LPS employed was purchased from Sigma; this is alleged to be contaminated with TLR2 agonists, suggesting that its proinflammatory effect was mediated by a combination of TLR2 and TLR4 activation. The adjuvant effect of LPS and zymosan were absent in mice deficient for the IL-1R-associated kinase 1 (IRAK1), suggesting that IL-1 or TLR signaling through the MYD88-independant pathway was involved $^{83}$.

Although agonists for individual TLRs, especially TLR2 and TLR9, may activate the innate immune responses that drive activation of self-reactive effector $\mathrm{T}$ cells, it appears that these responses are optimally driven by signals from two TLRs or a TLR and an NLR or CLR. This may reflect the need for priming and boosting stimuli. For example, production of mature active IL- $1 \beta$ requires priming with a TLR ligand to induce pro-IL-1 $\beta$ expression, and a second signal from a PAMP or DAMP to activate the NLR inflammasome complex and associated caspase-1, which cleaves the pro-IL-1 $\beta$ into its active form. Consistent with this, $M$. tuberculosis can provide both stimuli ${ }^{8}$, which may explain why it is more effective than individual TLR agonists in inducting experimental autoimmunity.

Modulation $T_{\text {Reg }}$ cells in autoimmunity. In addition to activating effector T cells, TLR agonists can indirectly or directly modulate the function of $\mathrm{T}_{\mathrm{Reg}}$ cells. There is evidence that TLR activation can block $\mathrm{T}_{\text {Reg }}$ cell responses, thereby breaking tolerance to self antigens ${ }^{84-86}$. IL-6 production by TLR-activated DCs can inhibit the suppressive function of $T_{\text {Reg }}$ cells ${ }^{85}$. 
Furthermore, IL-1 and IL-6 production by TLR-activated mature DCs is required to reverse $\mathrm{T}_{\text {Reg }}$ cell anergy induced by immature DCs ${ }^{87}$. However, it has also been reported that TLR4 and TLR9 agonists can promote IL-10-secreting $\mathrm{T}_{\text {Reg }}$ cells that inhibit $\mathrm{CD}^{+}$and $\mathrm{CD} 4^{+}$effector $\mathrm{T}$ cells ${ }^{13,88}$. This may be a strategy to limit immunopathology during infection, but may also control sterile inflammation and prevent the development of autoimmunity. The expansion of inducible $\mathrm{T}_{\text {Reg }}$ cells by TLR agonists appears to be mediated through TLR-induced production of IL-10, TGF $\beta$ and other immunosuppressive molecules from innate immune cells ${ }^{13}$. Indeed these regulatory mechanisms may prevent the induction of infection-driven autoimmunity in most individuals, but their failure or attenuation, perhaps by environmental factors, may increase the risks of developing autoimmune diseases.

\section{Direct modulation of T cells via TLRs}

Whereas it is well established that TLR signaling in innate immune cells can indirectly promote $\mathrm{T}$ cell differentiation and expansion through DC maturation and regulatory cytokine production, $\mathrm{T}$ cells also express TLRs and evidence is emerging that TLR signaling in $\mathrm{CD}^{+}$and $\gamma \delta \mathrm{T}$ cells can promote cytokine secretion or regulate their function (FIG 2).

Modulation of effector $C D 4^{+} T$ cells. TLR2 signaling in $\mathrm{T}_{\mathrm{H}} 1$ cells promotes their proliferation and IFN $\gamma$ production ${ }^{89}$. Moreover, stimulation with $\mathrm{CpG}$ restored the proliferation of highly purified naïve $\mathrm{T}$ cells from $P k c \theta^{-/-}$mice in response to $\mathrm{CD} 3$-specific antibody stimulation ${ }^{90}$. Protein kinase $\mathrm{C} \theta(\mathrm{PKC} \theta)$ is involved in $\mathrm{T}$ cell differentiation and $\mathrm{PKC} \theta$-deficient mice are resistant to experimental autoimmune myocarditis (EAM). Susceptibility to EAM was restored by in vivo administration of $\mathrm{CpG}^{90}$, suggesting that TLR ligands may act directly on $\mathrm{T}$ cells to induce autoimmunity in vivo. Finally, stimulation of $\mathrm{CD}^{+} \mathrm{T}$ cells with Pam $3 \mathrm{Cys}$ induced their proliferation and IL-17 production, which was enhanced by IL-23. By contrast, $T l r 2^{-/-}$mice were less susceptible to EAE and loss of TLR2 in $T_{H} 17$ cells reduced their ability to transfer EAE $^{62}$.

Modulation of CD8 T cells. $\mathrm{CD}^{+} \mathrm{T}$ cells are found in CNS lesions of patients with multiple sclerosis, where they appear to be involved in myelin degradation and neuronal damage ${ }^{91}$. Although the mechanism of self-reactive $\mathrm{CD}^{+} \mathrm{T}$ cell activation in autoimmune diseases is unclear, it may involve cross-presentation of autoantigens and bystander stimulation by PAMPs. 
It has been demonstrated that $\mathrm{CD}^{+} \mathrm{T}$ cells express $\mathrm{TLRs}^{92-93}$. Stimulation of with TLR2 agonists enhanced CD3-induced proliferation of murine $\mathrm{CD}^{+} \mathrm{T}$ cells by lowering the threshold for costimulatory signals $^{94}$. The TLR9 agonist $\mathrm{CpG}$ has been shown to promote IL- 8 release by purified human $\mathrm{CD}^{+} \mathrm{T}$ cells ${ }^{93}$. Thus TLR agonists may promote the activation of self-reactive $\mathrm{CD}^{+} \mathrm{T}$ cells in certain autoimmune diseases.

Modulation of $\gamma \delta$ T cells. It has been reported that $\gamma \delta$ T cells express TLR1, TLR2 and the CLR dectin-1, and secrete IL-17 in vitro following stimulation with TLR1 and TLR2 or TLR2 and dectin-1 ligands, particularly in the presence of exogenous IL-23 ${ }^{23}$. More recently it has been shown that IL-17-producing $\gamma \delta \mathrm{T}$ cells express higher levels of TLR1, TLR2, TLR4, TLR6 and TLR9 than IL-17-secreting CD4 T cells ${ }^{62}$. We have found that highly purified naive $\gamma \delta \mathrm{T}$ cells produce IL-17 in response to IL-1 $\beta$ and IL-23 ${ }^{6}$, or to PAMP-activated DCs in the absence of stimulation with CD3- or CD28-specific antibodies. However, highly purified $\gamma \delta \mathrm{T}$ cells failed to respond directly to TLR agonists alone $^{8}$ (C. E. Sutton and K. H. G Mills, unpublished observations). It is thus possible that certain subsets of $\gamma \delta \mathrm{T}$ cells are already differentiated in the periphery and produce IL-17 in response to local IL-23 $3^{95}$ or to IL-23 together with IL-1 that are induced by PAMP- or DAMP-activated innate immune cells ${ }^{6}$.

Modulation of $T_{R e g}$ cells. Murine $\mathrm{T}_{\text {Reg }}$ cells express TLR4, TLR5, TLR7 and TLR8 ${ }^{96}$ and there is evidence that TLR agonists can bind to them and modulate their function. Synthetic and natural ligands for TLR8 are capable of reversing the suppressive function of human $\mathrm{T}_{\mathrm{Reg}}$ cells ${ }^{84}$. Furthermore, persistent TLR activation can overcome the suppressive effect of $\mathrm{T}_{\text {Reg }}$ cells and abrogate tolerance to tumour cells ${ }^{86}$.

However, there are also reports that TLR agonists can directly enhance $\mathrm{T}_{\text {Reg }}$ cell function. It has been demonstrated that LPS can induce proliferation and enhance the suppressive function of $\mathrm{T}_{\text {Reg }}$ cells ${ }^{96}$. Human $\mathrm{T}_{\text {Reg }}$ cells express TLR5, and stimulation with flagellin and CD3-specific antibody enhances expression of forkhead box P3 (FOXP3) and their suppressive function ${ }^{97}$. The TLR2 ligand $\mathrm{Pam}_{3} \mathrm{Cys}$ induces proliferation of murine $\mathrm{T}_{\mathrm{Reg}}$ cells and although this was associated with a temporary loss of $\mathrm{T}_{\text {Reg }}$ cell suppressive activity, $\mathrm{T}_{\text {Reg }}$ cell function was restored following removal of the TLR agonist ${ }^{70}$. It has also been reported that a TLR2 agonist enhanced proliferation of $\mathrm{T}_{\mathrm{Reg}}$ cells and transiently suppressed FOXP3 expression, but also rendered 
$\mathrm{CD} 4^{+} \mathrm{CD} 25^{-}$effector cells resistant to suppression by $\mathrm{T}_{\mathrm{Reg}}$ cells ${ }^{98}$. Interestingly, it was recently reported that polysaccharide A from the gut commensal Bacteroides fragilis binds to TLR2 on $\mathrm{CD}^{+} \mathrm{T}$ cells promoting IL-10 production and the expansion of $\mathrm{T}_{\mathrm{Reg}}$ cells, which, in turn, inhibit $\mathrm{T}_{\mathrm{H}} 17$ cells. This suggests that TLR2 activation of $\mathrm{T}$ cells may promote tolerance, at least in the mucosa $^{99}$. Most of the evidence to date suggests that TLR activation of $\mathrm{T}$ cells is primarily indirect and mediated through TLR-induced activation of APCs. However, T cells do express TLRs and binding of TLR agonists to T cells can contribute to their activation, and this applies to both effector and regulatory $\mathrm{T}$ cells. Some of the strongest evidence is around TLR2 activation of $T_{\text {Reg }}$ cells, so from this perspective blocking TLR2 may attenuate $T_{\text {Reg }}$ function and might therefore be more applicable to treating cancer than autoimmunity. However, studies in knockout mice have suggested that TLR2 may be a good therapeutic target in certain autoimmune diseases. Therefore, further study is required to decipher the relative contribution of direct versus indirect activation of effector and regulatory T cells by TLRs in different autoimmune diseases.

\section{TLRs and other PPRs as drug targets for autoimmunity}

The increasing evidence that the innate and adaptive immune responses that mediate autoimmune diseases are driven by PAMP and DAMP binding to TLRs and other PRRs has motivated the assessment of TLR-specific blocking antibodies or inhibitors of TLR signaling in pre-clinical models of inflammatory and autoimmune disorders. Proof-of-principle has been provided by studies with TLR knockout mice. For example, experimental arthritis is attenuated in $T l r 4^{-1-}$ mice and this is associated with lower $\mathrm{T}_{\mathrm{H}} 17$ responses, suggesting that TLR4 may be a good upstream target for preventing IL-17 production in rheumatoid arthritis ${ }^{11}$. Indeed it has already been shown that a TLR4 antagonist can treat arthritis in two mouse models ${ }^{69}$.

A synthetic TLR4 antagonist, a lipid A mimetic CRX-526, has been shown to inhibit the development of DSS-induced colitis or colitis in multidrug resistant gene1a-deficient mice ${ }^{100}$. Similarly, a rat TLR4-specific monoclonal antibody, 1A6, reduced inflammation in DSS-induced colitis in mice ${ }^{101}$. A humanized TLR4-specific antibody has been developed by NovImmune and is currently undergoing preclinical evaluation as a potential therapy for inflammatory bowel disease. A lipid A antagonist, Eritoran ${ }^{\mathrm{TM}}$ (E5564) from Eisai Pharmaceutical, which interferes with the formation of the TLR4/MD-2/LPS complex is an effective inhibitor of LPS-induced 
shock in mice ${ }^{102}$, but did not meet its primary endpoint in patients with severe sepsis in a phase III clinical trial (http://www.eisai.com/news/enews201108pdf.pdf ).

TLR2 and nucleic acid binding TLRs are also major targets for a number of inflammatory and autoimmune diseases. EAE is attenuated in TLR2 ${ }^{-/-}$mice, suggesting that the TLR2 signaling pathway may be a drug target for the treatment or prevention of multiple sclerosis ${ }^{62}$. An antibody to TLR2 developed by Opsona Therapeutics has been shown to be effective in a murine model of myocardial ischemia reperfusion injury ${ }^{103}$, and a humanized version of the antibody (OPN-305) has recently entered phase I clinical trials.

Antagonists of TLR7, TLR8 or TLR9, including CpG 52364 (Pfizer), IRS-954 (Dynavax) and IM 3100 (Idera) have also shown efficacy in mouse models of SLE and other autoimmune diseases and have recently entered clinical trials ${ }^{5}$. These studies provide evidence that inhibition of TLR signaling in response to endogenous DAMPs is a safe therapeutic approach in humans and has the potential to treat inflammatory diseases that involve sterile inflammation.

Conclusions and perspectives Epidemiological studies have linked infection with the development or exacerbation of autoimmune disease. Furthermore, enhanced expression of TLRs and their agonists in diseased tissues provides indirect evidence that innate immune responses mediated though TLRs and other PRRs are involved in the development of autoimmune inflammation. More convincing evidence is provided from mouse models where defects in expression or signalling via TLRs are associated with attenuation of the innate and adaptive immune responses that mediate autoimmunity. Conversely, administration of exogenous TLR agonists to mice can promote or exacerbate autoimmunity.

In the absence of infection, sterile inflammation can be initiated by the release of DAMPs or alarmins from necrotic cells (FIG. 4). It has recently been suggested that pathogens and commensal microorganism-derived MAMPs bind to PRRs, but do not by themselves trigger host immune responses ${ }^{104}$. In order to overcome homeostatic immune regulation, innate immune cells require activation with MAMPs together with DAMPs released from host cells following injury or pathogen-induced cell death ${ }^{104}$. This is consistent with the association between infections and autoimmunity, but it is not compatible with the view that commensal bacteria alone can precipitate autoimmune diseases, unless the second signal for innate activation is provided by injury-induced cell death. 
Unless there is preferential expression of individual TLRs or their agonists in the affected tissues, there is likely to be redundancy between different TLRs, and between TLRs and other PRRs. Nevertheless, there is already evidence from mouse models that blocking a single TLR, especially TLR2, TLR4 or TLR9, may be sufficient for the inhibition of the innate responses that promote inflammation and autoimmunity. However, this effect may be disease-dependent as, for example, TLR4 blocking ameliorates arthritis and TLR2 inhibition dampens EAE.

Evidence from phase III clinical trials indicates that drugs that broadly inhibit innate immune responses or completely block the induction or function of effector $\mathrm{T}$ cells are likely to significantly compromise host protective immunity. For example, psoriasis patients treated with

an IL-12p40-specific antibody, ustekinumab ${ }^{105}$ (which blocks $\mathrm{T}_{\mathrm{H}} 1$ and $\mathrm{T}_{\mathrm{H}} 17$ responses), or gouty arthritis patients treated with an IL-1 $\beta$-specific blocking antibody, canakinumab (FDA Briefing document 21 2011; http://www.fda.gov/downloads/AdvisoryCommittees/CommitteesMeetingMaterials/ Drugs/ArthritisDrugsAdvisoryCommittee/UCM259596.pdf) had a higher incidence of infections, including serious infections, than controls. Although these new drugs have significantly improved efficacy over existing therapies, more selective inhibition of specific pathways involved in inflammation in a particular tissue or specific to a particular disease may not involve the same risks. If a single TLR is proven to have a dominant role in a particular autoimmune disease, it is possible that targeting TLRs, especially an extracellular TLR with an inhibitory antibody, may provide a safe and effective therapeutic approach for certain inflammatory and Tcell mediated autoimmune diseases.

\section{Acknowledgements}

Kingston Mills is supported by Science Foundation Ireland, The Irish Health Research Board, and Enterprise Ireland. I am grateful to Jean Fletcher, Caroline Sutton and Rowan Higgs for helpful discussions. 
Box 1. Toll-like Receptors - sensors of microbial molecules and danger signals.

Human Toll-like receptors (TLRs) are evolutionary conserved homologs of Drosophila Toll protein involved in embryonic development in Drosophila. TLR are expressed on the cell surface or intracellularly in many cell types, especially cells of the innate immune system, where they function to respond to infection or damage. TLRs are members of the pathogen recognition receptor (PPR) family that sense conserved exogenous molecules from pathogens, called pathogen-associated molecular patterns (PAMPs). However they also bind molecules from commensal bacteria and endogenous damage-associated molecular patters (DAMPs) from dead and dying cells. Ligands for TLRs include proteins, lipopetides and nucleic acids from bacteria, viruses, fungi, parasites, human cells and synthetic molecules.

Examples of pathogen-derived, endogenous and synthetic TLR agonists

\begin{tabular}{|c|c|c|c|c|}
\hline TLR & Expressed & Pathogen-derived agonist & $\begin{array}{c}\text { Endogenous } \\
\text { agonists }\end{array}$ & $\begin{array}{l}\text { Synthetic } \\
\text { agonists }\end{array}$ \\
\hline TLR $1 / 2$ & Extracellular & $\begin{array}{l}\text { Bacteria: peptidoglycan, lipoproteins, } \\
\text { LTA } \\
\text { Fungi: Zymosan }\end{array}$ & & $\mathrm{Pam}_{3} \mathrm{CSK}_{4}$ \\
\hline TLR2/6 & Extracellular & Bacteria: lipoproteins & veriscan & MALP-2 \\
\hline TLR3 & Intracellular & Virus: dsRNA & mRNA & Poly I:C \\
\hline TLR4 & Extracellular & $\begin{array}{l}\text { Bacteria: LPS } \\
\text { Virus: RSV fusion protein } \\
\text { Fungi: mannan } \\
\text { Protozoa: glycoinositolphospholipids }\end{array}$ & $\begin{array}{l}\text { Saturated } \\
\text { fatty acids, } \\
\beta \text {-defensins, } \\
\text { oxLDL and } \\
\text { amyloid- } \beta^{1}\end{array}$ & $\begin{array}{l}\text { Lipid A } \\
\text { derivatives }\end{array}$ \\
\hline TLR5 & Extracellular & Bacteria: flagellin & & \\
\hline TLR7/8 & Intracellular & Virus: ssRNA & Self RNA & $\begin{array}{l}\text { Imiquimod, } \\
\mathrm{R}-848\end{array}$ \\
\hline TLR9 & Intracellular & $\begin{array}{l}\text { Bacteria: CpG DNA } \\
\text { Virus: CpG DNA } \\
\text { Protozoa: CpG DNA, hemozoin }\end{array}$ & Self DNA & CpG-ODN \\
\hline TLR11 & Extracellular & $\begin{array}{l}\text { Uropathogenic bacteria } \\
\text { Protozoa: profilin-like molecule }\end{array}$ & & \\
\hline
\end{tabular}

${ }^{1}$ Oxidized LDL and amyloid- $\beta$ bind CD36 and a TLR4-TLR6 heterodimer. CpG-ODN, CpGcontaining oligodeoxynucleotides; dsRNA, double stranded RNA, oxLDL, oxidized low-density lipoprotein, LTA, lipoteichoic acid; MALP-2, mycoplasma macrophage-activating lipopeptide-2, RSV, respiratory syncytial virus; ssRNA, single stranded RNA; TLR, Toll-like receptor. 


\section{Box 2. Role of $T_{H} 17$ and $T_{H} 1$ cells in autoimmunity}

Prior to the discovery of $T$ helper $17\left(\mathrm{~T}_{\mathrm{H}} 17\right)$ cells, it was thought that $\mathrm{T}_{\mathrm{H}} 1$ cells were the primary pathogenic cell population in $\mathrm{T}$ cell-mediated autoimmune diseases. However, mice deficient in interferon- $\gamma$ (IFN $\gamma$ ) or interleukin-12 (IL-12) were found to have increased susceptibility to experimental autoimmune encephalitis (EAE) or collagen-induced arthritis (CIA) ${ }^{106-108}$. It was subsequently shown that $I l 17^{-1-}$ mice have reduced susceptibility to $\mathrm{EAE}^{109}$, and that myelinspecific $\mathrm{T}_{\mathrm{H}} 17$ cells from mice with EAE expanded in vitro with IL-23 can transfer EAE to naïve mice ${ }^{110}$. Furthermore, mice defective in IL-23, which is required for expansion of $\mathrm{T}_{\mathrm{H}} 17$ cells, are resistant to the induction of EAE and CIA ${ }^{106,111}$. Although there is considerable plasticity in $\mathrm{T}$ cell subtypes, it now appears that $\mathrm{T}_{\mathrm{H}} 17$ cells are a functionally distinct population of $\mathrm{CD}^{+} \mathrm{T}$ cells that are pathogenic in many autoimmune diseases ${ }^{2}$.

There is evidence that IFN $\gamma$ may suppress IL-17 production by $\mathrm{T}_{\mathrm{H}} 17$ cells ${ }^{21}$. This provided an explanation for the failure of IFN $\gamma$-specific blocking antibody therapy in multiple sclerosis and for the more severe EAE in $I f n g^{-/-}$mice $^{108}$. However, there is evidence from cell transfer studies that both $T_{H} 1$ and $T_{H} 17$ cell subsets have a pathogenic role in autoimmune inflammation, perhaps acting at a different stage of disease or recruiting different effector cells ${ }^{112}$. It has also been reported that transfer of $\mathrm{T}_{\mathrm{H}} 1$ cells induced experimental autoimmune uveitis (EAU) in naïve recipients, which was not inhibited by treatment with IL-17-specific blocking antibodies ${ }^{113}$. Furthermore, IFN $\gamma$ exacerbates disease in patients with multiple sclerosis ${ }^{114}$ and IFN $\gamma$ promotes IL-1 $\beta$ production by human macrophages ${ }^{115}$, which enhances IL17 production by $\mathrm{T}_{\mathrm{H}} 17$ cells. Finally, IL-17 and IFN $\gamma$ double positive $\mathrm{CD}^{+} \mathrm{T}$ cells have been found in the gut of patients with Crohn's disease ${ }^{116}$. It appears that $\mathrm{T}_{\mathrm{H}} 17$ and $\mathrm{T}_{\mathrm{H}} 1$ cells or IL$17^{+} \mathrm{IFN} \gamma^{+} \mathrm{CD} 4^{+} \mathrm{T}$ cells may have pathogenic roles in autoimmune and chronic inflammatory diseases, but their precise are still not fully resolved. 
Table 1. Effect of TLR deficiency or inhibition on autoimmune diseases in animal models

\begin{tabular}{|c|c|c|c|c|c|c|}
\hline Model & TLR & $\begin{array}{c}\text { Inter- } \\
\text { vention }\end{array}$ & $\begin{array}{c}\text { Innate } \\
\text { response }\end{array}$ & $\begin{array}{c}\text { T cell } \\
\text { response }\end{array}$ & Disease & Ref \\
\hline \multicolumn{7}{|l|}{ EAE } \\
\hline $\begin{array}{l}\text { MOG } \\
+\mathrm{CFA}\end{array}$ & MYD88 & KO & $\downarrow \mathrm{IL}-6, \mathrm{IL}-23$ & $\downarrow \mathrm{IL}-17$ & Resistant & 61 \\
\hline $\begin{array}{l}\text { MOG+ } \\
\text { CFA }\end{array}$ & $\begin{array}{l}\text { TLR4/ } \\
\text { TLR9 }\end{array}$ & KO & $\uparrow$ IL-6, IL-23 & 个IL-17 & Enhanced & 61 \\
\hline $\begin{array}{l}\text { MOG+ } \\
\text { CFA }\end{array}$ & MYD88 & KO & & $\downarrow \mathrm{IFN} \gamma$ & Resistant & 10 \\
\hline $\begin{array}{l}\text { MOG+ } \\
\text { CFA }\end{array}$ & TLR9 & KO & & & Reduced & 10 \\
\hline $\begin{array}{l}\text { MOG+ } \\
\text { CFA }\end{array}$ & TLR2 & KO & & & normal & 10 \\
\hline $\begin{array}{l}\text { MOG+ } \\
\text { CFA }\end{array}$ & TLR2 & KO & & $\downarrow$ IL-17 & Reduced & 62 \\
\hline $\begin{array}{l}\text { T cell } \\
\text { transfer }\end{array}$ & TLR2 & KO T cell & & $\begin{array}{l}\downarrow \mathrm{IL}-17, \\
\text { IFN } \gamma\end{array}$ & Abrogated & 62 \\
\hline \multicolumn{7}{|l|}{ Arthritis } \\
\hline Zymosan & TLR2 & KO & & & Reduced & 67 \\
\hline $\mathrm{IL}^{-1 \mathrm{Ra}^{-/-}}$ & TLR2 & KO & & $\begin{array}{l}\uparrow \text { IFN- } \gamma, \\
\text { IL-17 } \\
\downarrow \text { Foxp3 }\end{array}$ & Enhanced & 11 \\
\hline $\mathrm{IL}^{\mathrm{IL}} \mathrm{Ra}^{-{ }^{-I-}}$ & TLR4 & $\mathrm{KO}$ & & $\downarrow$ IL-17 & Reduced & 11 \\
\hline IL-1Ra'- & TLR9 & KO & & & No effect & $\pi$ \\
\hline $\mathrm{IL}-1 \mathrm{Ra}^{-{ }^{-1}}$ & TLR4 & Antagonist & & & Reduced & 69 \\
\hline CIA & TLR4 & Antagonist & $\downarrow \mathrm{IL}-1 \beta$ & & Reduced & 69 \\
\hline \multicolumn{7}{|l|}{ EAU } \\
\hline $\begin{array}{l}\text { IRBP+ } \\
\text { CFA }\end{array}$ & MYD88 & $\mathrm{KO}$ & & $\begin{array}{l}\downarrow \text { IFN- } \gamma, \\
\text { TNF- } \alpha\end{array}$ & Resistant & 71 \\
\hline $\begin{array}{l}\text { IRBP+ } \\
\text { CFA }\end{array}$ & $\begin{array}{l}\text { TLR2, } \\
3,4,9,\end{array}$ & $\mathrm{KO}$ & & & normal & 71,117 \\
\hline
\end{tabular}

CIA, collagen-induced arthritis; EAE, experimental autoimmune encephalomyelitis; EAU, experimental autoimmune uveitis; IRBP, interphotoreceptor retinoid binding protein; KO, knock out, MOG, myelin oligodendrocyte glycoprotein; TLR, Toll-like receptor 
Table 2. Induction or modulation of autoimmune diseases by TLR agonists in animal models.

\begin{tabular}{|c|c|c|c|c|c|c|c|}
\hline Model & TLR & Agonist & Intervention & $\begin{array}{c}\text { Innate } \\
\text { response }\end{array}$ & $\begin{array}{c}\text { T cell } \\
\text { response }\end{array}$ & Disease & Ref. \\
\hline \multicolumn{8}{|l|}{ EAE } \\
\hline $\begin{array}{l}\text { MOG+ } \\
\text { CFA }\end{array}$ & $\begin{array}{l}\text { TLR+ } \\
\text { dectin- } \\
1\end{array}$ & Zymosan & $\begin{array}{l}\text { MOG + IFA + } \\
\text { zymosan }\end{array}$ & $\begin{array}{l}\uparrow I L-6, \\
\text { IL-23, }\end{array}$ & $\uparrow$ IL-17 & $\begin{array}{l}\text { Induces } \\
\text { (transient) }\end{array}$ & 82 \\
\hline $\begin{array}{l}\text { MOG+ } \\
\text { CFA }\end{array}$ & $\begin{array}{l}\text { TLR4/ } \\
\text { TLR2 }\end{array}$ & $\begin{array}{l}\text { LPS/ } \\
\text { Zymosan }\end{array}$ & $\begin{array}{l}\text { MOG + IFA + } \\
\text { TLR agonist s.c. }\end{array}$ & & & Induces & 83 \\
\hline $\begin{array}{l}\text { MOG+ } \\
\text { CFA }\end{array}$ & TLR4 & LPS & $\begin{array}{l}\text { MOG + IFA + } \\
\text { LPS }\end{array}$ & & $\begin{array}{l}\text { 个IL-17, } \\
\text { IFN- } \gamma\end{array}$ & Mild & 62 \\
\hline $\begin{array}{l}\text { B10.S PLP } \\
\text { Tg }\end{array}$ & TLR9 & $\mathrm{CpG}$ & $\begin{array}{l}\mathrm{PLP}+\mathrm{IFA}+ \\
\mathrm{CpG}\end{array}$ & & & Enhances & 81 \\
\hline $\begin{array}{l}\text { PLP+ } \\
\text { CFA }\end{array}$ & TLR9 & $\mathrm{CpG}$ & $\begin{array}{l}\text { CpG, IFA + } \\
\text { PLP } \\
\text { immunization }\end{array}$ & & $\begin{array}{l}\text { 个IFN- } \gamma \text {, } \\
\text { low IL- } \\
17\end{array}$ & None & 80 \\
\hline $\begin{array}{l}\text { T cell } \\
\text { transfer }\end{array}$ & TLR9 & $\mathrm{CpG}$ & $\begin{array}{l}\text { CpG+PLP } \\
\text { immunization }\end{array}$ & & & Mild & 80 \\
\hline $\begin{array}{l}\mathrm{LN} \text { cell } \\
\text { transfer }\end{array}$ & TLR9 & $\mathrm{CpG}$ & $\begin{array}{l}\text { CpG activation } \\
\text { of LN cells from } \\
\text { PLP + IFA } \\
\text { primed mice }\end{array}$ & $\uparrow$ IL-12 & $\uparrow I F N-\gamma$ & Induces & 63 \\
\hline $\begin{array}{l}\text { PLP+ } \\
\text { CFA }\end{array}$ & TLR3 & Poly I:C & i.p. days $5,7,9$ & $\uparrow I F N-\beta$ & & Reduces & 65 \\
\hline \multicolumn{8}{|l|}{ Arthritis } \\
\hline \multirow[t]{2}{*}{$\begin{array}{l}\text { Adjuvant } \\
\text { arthritis }\end{array}$} & TLR9 & ISS-ODN & $\begin{array}{l}\text { Injection into } \\
\text { joint }\end{array}$ & & $\uparrow I F N-\gamma$ & Induces & 68 \\
\hline & TLR2 & PGN & Immunization & & & Induces & 68 \\
\hline CIA & TLR4 & LPS & $\begin{array}{l}\text { Type II collagen } \\
\text { + LPS i.p. }\end{array}$ & $\begin{array}{l}\uparrow I L-12, \\
\text { IL-1 } \beta \text {, } \\
\text { TNF- } \alpha \text {, } \\
\text { IFN- } \gamma\end{array}$ & & Induces & 118 \\
\hline $\begin{array}{l}\text { Cell } \\
\text { transfer } \\
\text { from } \\
\text { pristine- } \\
\text { primed }\end{array}$ & $\begin{array}{l}\text { TLR } \\
7,9\end{array}$ & $\begin{array}{l}\text { Nucleic } \\
\text { acids }\end{array}$ & $\begin{array}{l}\text { Spleen cells } \\
\text { stimulation with } \\
\text { heterogenous } \\
\text { ribonucleoprotei } \\
\text { ns }\end{array}$ & $\begin{array}{l}\uparrow I L-6, \\
\text { TNF- } \alpha\end{array}$ & & Induces & 60 \\
\hline $\begin{array}{l}\text { Cell } \\
\text { transfer } \\
\text { from } \\
\text { pristine- } \\
\text { primed }\end{array}$ & $\begin{array}{l}\text { TLR3 } \\
\text { TLR9 } \\
\text { TLR7 }\end{array}$ & $\begin{array}{l}\text { polyI:C, } \\
\text { ODN, } \\
\text { imiquimod }\end{array}$ & $\begin{array}{l}\text { Spleen cells } \\
\text { stimulation with } \\
\text { TLR agonists }\end{array}$ & & & Induces & 60 \\
\hline
\end{tabular}




\begin{tabular}{|c|c|c|c|c|c|c|c|}
\hline IL-rat & TLR4 & LPS & i.p. injection & & & Enhanced & $\pi 1$ \\
\hline IL-ra $^{-/-}$ & TLR2 & Pam3Cys & i.p. injection & & & Enhanced & 11 \\
\hline \multicolumn{8}{|l|}{ Other } \\
\hline $\begin{array}{l}\text { Antibody- } \\
\text { associated } \\
\text { vasculitis }\end{array}$ & TLR2 & $\mathrm{Pam}_{3} \mathrm{CSK}_{4}$ & $\begin{array}{l}\text { Immunization } \\
\text { myeloperoxidas } \\
\text { e + TLR agonist }\end{array}$ & & $\uparrow \mathrm{IL}-17$ & Induces & 73 \\
\hline $\begin{array}{l}\text { Antibody- } \\
\text { associated } \\
\text { vasculitis }\end{array}$ & TLR9 & $\mathrm{CpG}$ & $\begin{array}{l}\text { Immunization } \\
\text { myeloperoxidas } \\
\text { e + TLR agonist }\end{array}$ & & $\uparrow I F N-\gamma$ & Induces & 73 \\
\hline Psoriasis & $\begin{array}{l}\text { TLR7/ } \\
\text { TLR8 }\end{array}$ & $\begin{array}{l}\text { Imiquimo } \\
\mathrm{d}\end{array}$ & $\begin{array}{l}\text { Topical } \\
\text { application }\end{array}$ & IL-23 & $\uparrow \mathrm{IL}-17$ & Induces & 74 \\
\hline$\overline{\text { EAU }}$ & TLR4 & LPS & $\begin{array}{l}\text { IRBP+CFA+LP } \\
\mathrm{S}\end{array}$ & $\begin{array}{l}\uparrow \text { IL-6, } \\
\text { IL-1 } \beta \text {, } \\
\text { TNF- } \alpha \text {, } \\
\text { IFN- } \gamma \text {, }\end{array}$ & $\begin{array}{l}\uparrow I F N-\gamma, \\
\text { IL-17 }\end{array}$ & Enhances & 117 \\
\hline Myocarditis & TLR9 & $\mathrm{CpG}$ & $\begin{array}{l}\text { CpG i.p. PKC- } \theta^{-} \\
\text {/- mice } \\
\text { before/after } \\
\text { immunization } \\
\text { with } \\
\text { myosin+CFA }\end{array}$ & & $\begin{array}{l}\uparrow I L-17, \\
\text { TNF- } \alpha\end{array}$ & Induces & 90 \\
\hline
\end{tabular}

CIA, collagen-induced arthritis; CFA, complete Freund's adjuvant; CpG-ODN, CpG-containing oligodeoxynucleotides; IFA, incomplete Freund's adjuvant; DSS, dextran sulfate sodium; EAE, experimental autoimmune encephalomyelitis; EAU, experimental autoimmune uveitis; KO, knock out, LPS, i.g. intra-gastric; ISS-ODN immunostimulatry sequence-containing oligodeoxynucleotides; i.p., intra-peritoneal; i.r., intra-rectal; IRBP, interphotoreceptor retinoid binding protein, lipopolysaccharide; LTA, lipoteichoic acid; LN, lymph node, MOG, myelin oligodendrocyte glycoprotein; PLP, proteolipid protein; s.c., subcutaneous; Tg, transgenic; TLR, Toll-like receptor; TNBS, trinitrobenzene sulfonic acid. 


\section{Figure Legends}

Figure 1. Bacteria-induced signaling in innate immune cells leading to $\mathbf{T}$ cell-promoting cytokine production. With the exception of Toll-like receptor 3 (TLR3), each of the TLRs employ myeloid differentiation primary response protein 88 (MYD88) as an adapter protein. In addition, TLR4 and TLR2 utilize MYD88-adapter-like (MAL), whereas Toll-interleukin-1 resistance (TIR) domain-containing adaptor-inducing interferon- $\beta$ (TRIF) and TRIF-related adapter molecule (TRAM) are required for TLR3- and TLR4-mediated type I interferon (IFN) production. The figure illustrates some of the signalling pathways induced in a dendritic cell in response to a Gram-negative bacterium. Lipopolysaccharide (LPS) from the bacteria binds TLR4 in complex with MD2 and this complex initiates signalling by recruiting the adapter proteins MYD88, MAL, TRIF and TRAM. MYD88 associates with interleukin (IL)-1 receptor associated kinase 1(IRAK1) and IRAK4 and recruits tumor necrosis (TNF) receptor-associated factor 6 (TRAF6). This complex recruits transforming growth factor- $\beta$-activated kinase 1 (TAK1) leading to phosphorylation of $\mathrm{IkB}$ and activation of nuclear factor- $\kappa \mathrm{B}(\mathrm{NF}-\kappa \mathrm{B})$ and consequent transcription of a range of genes coding for pro-inflammatory cytokines, including TNF $\alpha$, interleukin 6 (IL-6), pro-IL-1 $\beta$ and pro-IL-18. In addition, TLR agonists activate the interferon regulatory factor (IRF) pathways, leading to IL-12p35 and type I IFN production. TLR-induced activation of TAK-1 also results in phosphorylation of mitogen activated protein kinases (MAPK), including p38 and ERK. Phosphorylation of ERK promotes transcription of IL-23p19 and IL-23 production. Phosphorylation of p38 activates cAMP response element-binding (CREB) leading to IL-10 production. Bacterial molecules, also bind intracellular nucleotidebinding oligomerization domain (NOD)-like receptor (NLRs), such as NOD-1 or NOD-2, which activate NF- $\kappa \mathrm{B}$ and MAP kinases. Activation of NLRs, such as NLRP3, the associated inflammasome complex and caspase- 1 facilitates the processing of pro-IL-1 $\beta$ and pro-IL-18 into mature cytokines. IL-12 promotes T helper $1\left(\mathrm{~T}_{\mathrm{H}} 1\right)$ cell differentiation, IL-10 induces regulatory $\mathrm{T}\left(\mathrm{T}_{\mathrm{Reg}}\right.$ cells and IL-1, IL-6, IL-18 and IL-23 promote $\mathrm{T}_{\mathrm{H}} 17$ cell differentiation or expansion.

Figure 2. Effector cells and drug targets in autoimmunity. Toll-like receptor (TLR) agonists activate innate immune cells, such as dendritic cells (DC), promoting release of inflammatory cytokines, including interleukin 12 (IL-12), which induces $\mathrm{T}_{\mathrm{H}} 1$ differentiation, and IL-6, which 
works with transforming growth factor- $\beta$ (TGF- $\beta$ ) to promote differentiation of $\mathrm{T}_{\mathrm{H}} 17$ cells. $\mathrm{T}_{\mathrm{H}} 17$ cells are further activated by IL-1 and IL-23, but also by IL-17 and IL-21 produced early in the immune response by $\gamma \delta \mathrm{T}$ cells and other innate lymphoid cells (ILC). Interferon- $\gamma$ (IFN $\gamma$ ) produced by $T_{H} 1$ cells activates macrophages, promoting release of inflammatory mediators, such as IL-1 $\beta$, tumor necrosis factor (TNF), matrix metalloproteinases (MMPs) and reactive oxygen species (ROS), which mediate tissue damage. IL-17 induces chemokine production, especially macrophage inflammatory protein (MIP)-2/IL-8, which recruits neutrophils to the site of inflammation. Finally, granulocyte-macrophage colony-stimulating factor (GM-CSF) produced by both $\mathrm{T}_{\mathrm{H}} 1$ and $\mathrm{T}_{\mathrm{H}} 17$ cells activates $\mathrm{DC}$ and macrophages and appears to be essential for the development of autoimmunity. Biological response modifying drugs that are in use or in pre-clinical or clinical evaluation target many of the cytokines or the intracellular signaling molecules in innate cells or T cells.

Figure 3. Indirect and direct activation of $T$ cells by TLR agonists. Pathogen-associated molecular patterns (PAMPs), bind to pathogen recognition receptors (PRRs), including Toll-like receptor (TLR), but also NOD-like receptors (NLR), C-type lectin receptors (CLR), and RIG-Ilike receptors (RLR). TLR activation promotes co-stimulatory molecule (CD80 and CD86) and major histocompatability complex (MHC) expression (maturation) of immature dendritic cells (iDC) making them capable of activating naïve T cells. TLR-activated DC and macrophages (Mac) act as a source of immunomodulatory cytokines for directing differentiation of $\mathrm{T}$ helper 1 $\left(\mathrm{T}_{\mathrm{H}} 1\right)$ or $\mathrm{T}_{\mathrm{H}} 17$ cells. DC and macrophage-derived interleukin 12 (IL-12) promotes differentiation of naïve $\mathrm{T}$ cells into $\mathrm{T}_{\mathrm{H}} 1$ cells either directly or via interferon- $\gamma$ (IFN $\gamma$ ) production from natural killer (NK) cells. Activated $\mathrm{T}_{\mathrm{H}} 1$ cells secrete further IFN $\gamma$. IL-6 and transforming growth factor$\beta$ (TGF $\beta$ ) promote differentiation of naïve $T$ cells into $T_{H} 17$ cells. IL-1 $\beta$, IL- $1 \alpha$ or IL-18 in synergy with IL-23 activate $\mathrm{T}_{\mathrm{H}} 17$ cells, inducing their proliferation and IL-17 secretion. $\gamma \delta \mathrm{T}$ cells also secrete IL-17, IL-21 and IL-22 following stimulation with IL-1 $\beta$, IL-1 $\alpha$ or IL-18 with IL-23 released by PAMP activated DC or macrophages; this does not require association between the DC and $\gamma \delta \mathrm{T}$ cell or stimulation through the T cell receptor engagement. IL-21 and IL-17 produced by $\gamma \delta \mathrm{T}$ cells stimulate further differentiation of $\mathrm{T}_{\mathrm{H}} 17$ cells. There is also some evidence that TLR agonists may act directly on $\mathrm{CD}^{+} \mathrm{T}$ cells and $\gamma \delta \mathrm{T}$ cells, promoting 
proliferation and cytokine production. However, in the case of $\mathrm{T}_{\mathrm{H}} 17$ cells, this appears to require co-operation with IL-23.

Figure 4. Infection, PAMP- and DAMP-mediated activation of inflammatory responses. Optimum activation of inflammatory responses in innate immune cells, such as dendritic cells (DC) and macrophages (MØ) appears to require two signals, which can be derived from exogenous microbe-derived or endogenous host-derived molecules. For example, interleukin (IL)-1 $\beta$ or IL-18 production requires priming of the cell through a Toll-like receptor (TLR) to promote production of the pro-form of the cytokines and the processing of these cytokines is mediated by caspase- 1 induced by a second signal provided by a pathogen-associated molecular patterns (PAMP) or a damage-associated molecular pattern (DAMP). Three, non mutually exclusive, models of inflammatory responses involving PRRs are illustrated. a) PAMPs from pathogens or commensal bacteria including TLR agonists, but also ligands for NOD-like receptors (NLR), C-type lectin receptors (CLR) and inflammasome activators that mediate induction of inflammatory cytokines in response to infection. b) DAMPs or alarmins released from dead or dying cells include TLR agonists and inflammasome activators, such as ATP, that mediate induction of inflammatory cytokine production from tissue in response to injury or stress. IL- $1 \alpha$ which is released from necrotic cells is also a key alarmin driving sterile inflammation. c). Microbe-associated molecular patterns (MAMPs) from pathogens or commensal bacteria including TLR-, NLR-, and CLR- agonists and inflammasome activators activate innate, in combination with DAMPs released from pathogen-infected or damaged host cells mediate induction of inflammatory cytokines in response to pathogens. 


\section{References}

1. Janeway, C.A., Jr. \& Medzhitov, R. Innate immune recognition. Annu Rev Immunol 20, 197-216. (2002).

2. Mills, K.H. Induction, function and regulation of IL-17-producing T cells. Eur J Immunol 38, 2636-2649 (2008).

3. Wing, K. \& Sakaguchi, S. Regulatory T cells exert checks and balances on self tolerance and autoimmunity. Nat Immunol 11, 7-13 (2010).

4. Akira, S., Uematsu, S. \& Takeuchi, O. Pathogen recognition and innate immunity. Cell 124, 783-801 (2006).

5. Hennessy, E.J., Parker, A.E. \& O'Neill, L.A. Targeting Toll-like receptors: emerging therapeutics? Nat Rev Drug Discov 9, 293-307 (2010).

6. Sutton, C.E., et al. Interleukin-1 and IL-23 Induce Innate IL-17 Production from gammadelta T Cells, Amplifying Th17 Responses and Autoimmunity. Immunity 31, 331341 (2009).

The first report that $\gamma \delta \mathrm{T}$ cells promote autoimmune inflammation by providing a source of innate IL-17 and IL-21.

7. van Beelen, A.J., et al. Stimulation of the Intracellular Bacterial Sensor NOD2 Programs Dendritic Cells to Promote Interleukin-17 Production in Human Memory $\mathrm{T}$ Cells. Immunity 27, 660-669 (2007).

The first report that sensing of PAMPs though Nod-Like receptors promotes development of human Th17 cells.

8. Lalor, S.J., et al. Caspase-1-processed cytokines IL-1beta and IL-18 promote IL-17 production by gammadelta and CD4 T cells that mediate autoimmunity. J Immunol 186, 5738-5748 (2011).

Defined a role for PAMP-driven IL-18 as well as IL-1 in driving IL-17 production by CD4 and $\gamma \delta \mathrm{T}$ cells that are pathogenic in autoimmune diseases.

9. Ivanov, II, et al. Induction of intestinal Th17 cells by segmented filamentous bacteria. Cell 139, 485-498 (2009).

This study demonstrated that certain strains of commensal bacteria promote the induction of Th17 cells in the intestine, suggesting that mirobiata may precipitate autoimmunity.

10. Prinz, M., et al. Innate immunity mediated by TLR9 modulates pathogenicity in an animal model of multiple sclerosis. Journal of Clinical Investigation 116, 456-464 (2006).

This study demonstrated that signalling thorough MyD88 and TLR9 was required to promote the innate cytokines that drive the induction of Th17 cells in experimental autoimmunity.

11. Abdollahi-Roodsaz, S., et al. Stimulation of TLR2 and TLR4 differentially skews the balance of T cells in a mouse model of arthritis. J Clin Invest 118, 205-216 (2008).

This study demonstrated that TLR4 may be an important drug target for rheumatoid arthritis; activation of TLR4 by microbial flora promoted $T$ cell that were pathogenic in an arthritis model and disease was blocked using a TLR4 antagonist.

12. Brereton, C.F., Sutton, C.E., Lalor, S.J., Lavelle, E.C. \& Mills, K.H. Inhibition of ERK MAPK suppresses IL-23- and IL-1-driven IL-17 production and attenuates autoimmune disease. J Immunol 183, 1715-1723 (2009). 
13. Jarnicki, A.G., et al. Attenuating regulatory $\mathrm{T}$ cell induction by TLR agonists through inhibition of p38 MAPK signaling in dendritic cells enhances their efficacy as vaccine adjuvants and cancer immunotherapeutics. J Immunol 180, 3797-3806 (2008).

14. Conroy, H., Marshall, N.A. \& Mills, K.H. TLR ligand suppression or enhancement of Treg cells? A double-edged sword in immunity to tumours. Oncogene 27, 168-180 (2008).

15. Higgins, S.C. \& Mills, K.H. TLR, NLR Agonists, and Other Immune Modulators as Infectious Disease Vaccine Adjuvants. Curr Infect Dis Rep 12, 4-12 (2010).

16. Bettelli, E., et al. Reciprocal developmental pathways for the generation of pathogenic effector TH17 and regulatory T cells. Nature 441, 235-238 (2006).

17. Mangan, P.R., et al. Transforming growth factor-beta induces development of the $\mathrm{T}(\mathrm{H}) 17$ lineage. Nature 441, 231-234 (2006).

18. Veldhoen, M., Hocking, R.J., Atkins, C.J., Locksley, R.M. \& Stockinger, B. TGFbeta in the context of an inflammatory cytokine milieu supports de novo differentiation of IL-17producing T cells. Immunity 24, 179-189 (2006).

19. Sutton, C., Brereton, C., Keogh, B., Mills, K.H. \& Lavelle, E.C. A crucial role for interleukin (IL)-1 in the induction of IL-17-producing T cells that mediate autoimmune encephalomyelitis. J Exp Med 203, 1685-1691 (2006).

20. Aggarwal, S., Ghilardi, N., Xie, M.H., de Sauvage, F.J. \& Gurney, A.L. Interleukin-23 promotes a distinct $\mathrm{CD} 4 \mathrm{~T}$ cell activation state characterized by the production of interleukin-17. J Biol Chem 278, 1910-1914 (2003).

21. Harrington, L.E., et al. Interleukin 17-producing CD4+ effector T cells develop via a lineage distinct from the $\mathrm{T}$ helper type 1 and 2 lineages. Nat Immunol 6, 1123-1132 (2005).

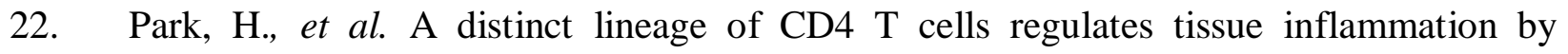
producing interleukin 17. Nat Immunol 6, 1133-1141 (2005).

23. Martin, B., Hirota, K., Cua, D.J., Stockinger, B. \& Veldhoen, M. Interleukin-17producing gammadelta $\mathrm{T}$ cells selectively expand in response to pathogen products and environmental signals. Immunity 31, 321-330 (2009).

24. Rachitskaya, A.V., et al. Cutting Edge: NKT Cells Constitutively Express IL-23 Receptor and ROR \{gamma\}t and Rapidly Produce IL-17 upon Receptor Ligation in an IL-6Independent Fashion. J Immunol 180, 5167-5171 (2008).

25. Takatori, H., et al. Lymphoid tissue inducer-like cells are an innate source of IL-17 and IL-22. J Exp Med 206, 35-41 (2009).

26. Murphy, A.C., Lalor, S.J., Lynch, M.A. \& Mills, K.H. Infiltration of Th1 and Th17 cells and activation of microglia in the CNS during the course of experimental autoimmune encephalomyelitis. Brain Behav Immun 24, 641-651 (2010).

27. Park, Y., Park, S., Yoo, E., Kim, D. \& Shin, H. Association of the polymorphism for Toll-like receptor 2 with type 1 diabetes susceptibility. Ann N Y Acad Sci 1037, 170-174 (2004).

28. Hong, J., et al. TLR2, TLR4 and TLR9 polymorphisms and Crohn's disease in a New Zealand Caucasian cohort. J Gastroenterol Hepatol 22, 1760-1766 (2007).

29. van Heel, D.A., et al. Synergy between TLR9 and NOD2 innate immune responses is lost in genetic Crohn's disease. Gut 54, 1553-1557 (2005).

30. Kamradt, T., Goggel, R. \& Erb, K.J. Induction, exacerbation and inhibition of allergic and autoimmune diseases by infection. Trends Immunol 26, 260-267 (2005). 
31. Serafini, B., et al. Dysregulated Epstein-Barr virus infection in the multiple sclerosis brain. J Exp Med 204, 2899-2912 (2007).

32. Buljevac, D., et al. Prospective study on the relationship between infections and multiple sclerosis exacerbations. Brain 125, 952-960 (2002).

33. Correale, J., Fiol, M. \& Gilmore, W. The risk of relapses in multiple sclerosis during systemic infections. Neurology 67, 652-659 (2006).

34. Saal, J.G., et al. Persistence of B19 parvovirus in synovial membranes of patients with rheumatoid arthritis. Rheumatol Int 12, 147-151 (1992).

35. Saal, J.G., et al. Synovial Epstein-Barr virus infection increases the risk of rheumatoid arthritis in individuals with the shared HLA-DR4 epitope. Arthritis Rheum 42, 1485-1496 (1999).

36. Abraham, C. \& Medzhitov, R. Interactions between the host innate immune system and microbes in inflammatory bowel disease. Gastroenterology 140, 1729-1737 (2011).

37. Wu, H.J., et al. Gut-residing segmented filamentous bacteria drive autoimmune arthritis via T helper 17 cells. Immunity 32, 815-827 (2010).

38. Atarashi, K., et al. ATP drives lamina propria $\mathrm{T}(\mathrm{H}) 17$ cell differentiation. Nature 455, 808-812 (2008).

39. Feng, T., Wang, L., Schoeb, T.R., Elson, C.O. \& Cong, Y. Microbiota innate stimulation is a prerequisite for $\mathrm{T}$ cell spontaneous proliferation and induction of experimental colitis. J Exp Med 207, 1321-1332 (2010).

40. Herrmann, I., et al. Streptococcus pneumoniae Infection aggravates experimental autoimmune encephalomyelitis via Toll-like receptor 2. Infect Immun 74, 4841-4848 (2006).

41. Schrijver, I.A., Melief, M.J., Tak, P.P., Hazenberg, M.P. \& Laman, J.D. Antigenpresenting cells containing bacterial peptidoglycan in synovial tissues of rheumatoid arthritis patients coexpress costimulatory molecules and cytokines. Arthritis Rheum 43, 2160-2168 (2000).

42. Klasen, I.S., et al. The presence of peptidoglycan-polysaccharide complexes in the bowel wall and the cellular responses to these complexes in Crohn's disease. Clin Immunol Immunopathol 71, 303-308 (1994).

43. Visser, L., et al. Phagocytes containing a disease-promoting Toll-like receptor/Nod ligand are present in the brain during demyelinating disease in primates. Am J Pathol 169, 1671-1685 (2006).

44. Schrijver, I.A., et al. Bacterial peptidoglycan and immune reactivity in the central nervous system in multiple sclerosis. Brain 124, 1544-1554 (2001).

45. Bsibsi, M., Ravid, R., Gveric, D. \& van Noort, J.M. Broad expression of Toll-like receptors in the human central nervous system. J Neuropathol Exp Neurol 61, 1013-1021 (2002).

46. Rajan, N. \& Langtry, J.A. Generalized exacerbation of psoriasis associated with imiquimod cream treatment of superficial basal cell carcinomas. Clin Exp Dermatol 31, 140-141 (2006).

47. Bach, J.F. The effect of infections on susceptibility to autoimmune and allergic diseases. N Engl J Med 347, 911-920 (2002).

48. Maizels, R.M. \& Yazdanbakhsh, M. T-cell regulation in helminth parasite infections: implications for inflammatory diseases. Chem Immunol Allergy 94, 112-123 (2008). 
49. Strachan, D.P. Family size, infection and atopy: the first decade of the "hygiene hypothesis". Thorax 55 Suppl 1, S2-10 (2000).

50. Walsh, K.P., Brady, M.T., Finlay, C.M., Boon, L. \& Mills, K.H. Infection with a helminth parasite attenuates autoimmunity through TGF-beta-mediated suppression of Th17 and Th1 responses. J Immunol 183, 1577-1586 (2009).

51. Ochoa-Reparaz, J., et al. Central nervous system demyelinating disease protection by the human commensal Bacteroides fragilis depends on polysaccharide A expression. $J$ Immunol 185, 4101-4108 (2010).

52. Seong, S.Y. \& Matzinger, P. Hydrophobicity: an ancient damage-associated molecular pattern that initiates innate immune responses. Nat Rev Immunol 4, 469-478 (2004).

53. Oppenheim, J.J. \& Yang, D. Alarmins: chemotactic activators of immune responses. Curr Opin Immunol 17, 359-365 (2005).

54. Bianchi, M.E. DAMPs, PAMPs and alarmins: all we need to know about danger. $J$ Leukoc Biol 81, 1-5 (2007).

55. Yanai, H., et al. HMGB proteins function as universal sentinels for nucleic-acid-mediated innate immune responses. Nature 462, 99-103 (2009).

56. Li, J., et al. Expression of high mobility group box chromosomal protein 1 and its modulating effects on downstream cytokines in systemic lupus erythematosus. $J$ Rheumatol 37, 766-775 (2010).

57. Chen, C.J., et al. Identification of a key pathway required for the sterile inflammatory response triggered by dying cells. Nat Med 13, 851-856 (2007).

58. Farez, M.F., et al. Toll-like receptor 2 and poly(ADP-ribose) polymerase 1 promote central nervous system neuroinflammation in progressive EAE. Nat Immunol 10, 958-964 (2009).

59. Sacre, S.M., et al. The Toll-like receptor adaptor proteins MyD88 and Mal/TIRAP contribute to the inflammatory and destructive processes in a human model of rheumatoid arthritis. Am J Pathol 170, 518-525 (2007).

60. Hoffmann, M.H., et al. Nucleic acid-stimulated antigen-presenting cells trigger $\mathrm{T}$ cells to induce disease in a rat transfer model of inflammatory arthritis. J Autoimmun 36, 288-300 (2011).

61. Marta, M., Andersson, A., Isaksson, M., Kampe, O. \& Lobell, A. Unexpected regulatory roles of TLR4 and TLR9 in experimental autoimmune encephalomyelitis. Eur J Immunol 38, 565-575 (2008).

62. Reynolds, J.M., et al. Toll-like Receptor 2 Signaling in CD4(+) T Lymphocytes Promotes $\mathrm{T}$ Helper 17 Responses and Regulates the Pathogenesis of Autoimmune Disease. Immunity 32, 692-702 (2010).

63. Ichikawa, H.T., Williams, L.P. \& Segal, B.M. Activation of APCs through CD40 or Tolllike receptor 9 overcomes tolerance and precipitates autoimmune disease. J Immunol 169, 2781-2787 (2002).

This study demonstrated that innate immune cell activation and IL-12 induction through TLR9 promoted $\mathrm{T}$ cell that are pathogenic in experimental autoimmune encephalomyelitis

64. Hall, J.A., et al. Commensal DNA limits regulatory $\mathrm{T}$ cell conversion and is a natural adjuvant of intestinal immune responses. Immunity 29, 637-649 (2008). 
65. Touil, T., Fitzgerald, D., Zhang, G.X., Rostami, A. \& Gran, B. Cutting Edge: TLR3 stimulation suppresses experimental autoimmune encephalomyelitis by inducing endogenous IFN-beta. J Immunol 177, 7505-7509 (2006).

66. Onta, T., et al. Induction of acute arthritis in mice by peptidoglycan derived from grampositive bacteria and its possible role in cytokine production. Microbiol Immunol 37, 573582 (1993).

67. Frasnelli, M.E., Tarussio, D., Chobaz-Peclat, V., Busso, N. \& So, A. TLR2 modulates inflammation in zymosan-induced arthritis in mice. Arthritis Res Ther 7, R370-379 (2005).

68. Ronaghy, A., et al. Immunostimulatory DNA sequences influence the course of adjuvant arthritis. J Immunol 168, 51-56 (2002).

69. Abdollahi-Roodsaz, S., et al. Inhibition of Toll-like receptor 4 breaks the inflammatory loop in autoimmune destructive arthritis. Arthritis Rheum 56, 2957-2967 (2007).

70. Sutmuller, R.P., et al. Toll-like receptor 2 controls expansion and function of regulatory T cells. J Clin Invest 116, 485-494 (2006).

71. Su, S.B., et al. Essential role of the MyD88 pathway, but nonessential roles of TLRs 2, 4, and 9 , in the adjuvant effect promoting Th1-mediated autoimmunity. J Immunol 175, 6303-6310 (2005).

72. Kim, H.S., et al. Toll-like receptor 2 senses beta-cell death and contributes to the initiation of autoimmune diabetes. Immunity 27, 321-333 (2007).

73. Summers, S.A., et al. Toll-like receptor 2 induces Th17 myeloperoxidase autoimmunity while Toll-like receptor 9 drives Th1 autoimmunity in murine vasculitis. Arthritis Rheum 63, 1124-1135 (2011).

74. van der Fits, L., et al. Imiquimod-induced psoriasis-like skin inflammation in mice is mediated via the IL-23/IL-17 axis. J Immunol 182, 5836-5845 (2009).

75. Evans, H.G., Suddason, T., Jackson, I., Taams, L.S. \& Lord, G.M. Optimal induction of $\mathrm{T}$ helper 17 cells in humans requires $\mathrm{T}$ cell receptor ligation in the context of Toll-like receptor-activated monocytes. Proc Natl Acad Sci U S A 104, 17034-17039 (2007).

76. Higgins, S.C., Jarnicki, A.G., Lavelle, E.C. \& Mills, K.H. TLR4 mediates vaccineinduced protective cellular immunity to Bordetella pertussis: role of IL-17-producing T cells. J Immunol 177, 7980-7989 (2006).

77. Acosta-Rodriguez, E.V., et al. Surface phenotype and antigenic specificity of human interleukin 17-producing T helper memory cells. Nat Immunol 8, 639-646 (2007).

78. LeibundGut-Landmann, S., et al. Syk- and CARD9-dependent coupling of innate immunity to the induction of T helper cells that produce interleukin 17. Nat Immunol 8, 630-638 (2007).

79. Ivanov, II, et al. Specific microbiota direct the differentiation of IL-17-producing Thelper cells in the mucosa of the small intestine. Cell Host Microbe 4, 337-349 (2008).

80. Tigno-Aranjuez, J.T., Jaini, R., Tuohy, V.K., Lehmann, P.V. \& Tary-Lehmann, M. Encephalitogenicity of complete Freund's adjuvant relative to $\mathrm{CpG}$ is linked to induction of Th17 cells. J Immunol 183, 5654-5661 (2009).

81. Waldner, H., Collins, M. \& Kuchroo, V.K. Activation of antigen-presenting cells by microbial products breaks self tolerance and induces autoimmune disease. J Clin Invest 113, 990-997 (2004).

This study demonstrated that activation of antigen presenting cells with a TLR9 agonist can promote self-reactive $\boldsymbol{T}$ cells that mediated autoimmunity in mice. 
82. Veldhoen, M., Hocking, R.J., Flavell, R.A. \& Stockinger, B. Signals mediated by transforming growth factor-beta initiate autoimmune encephalomyelitis, but chronic inflammation is needed to sustain disease. Nat Immunol 7, 1151-1156 (2006).

83. Hansen, B.S., Hussain, R.Z., Lovett-Racke, A.E., Thomas, J.A. \& Racke, M.K. Multiple toll-like receptor agonists act as potent adjuvants in the induction of autoimmunity. Journal of Neuroimmunology 172, 94-103 (2006).

84. Peng, G., et al. Toll-like receptor 8-mediated reversal of CD4+ regulatory T cell function. Science 309, 1380-1384 (2005).

85. Pasare, C. \& Medzhitov, R. Toll pathway-dependent blockade of CD4+CD25+ T cellmediated suppression by dendritic cells. Science 299, 1033-1036. (2003).

86. Yang, Y., Huang, C.T., Huang, X. \& Pardoll, D.M. Persistent Toll-like receptor signals are required for reversal of regulatory T cell-mediated CD8 tolerance. Nat Immunol 5, 508-515 (2004).

87. Kubo, T., et al. Regulatory $\mathrm{T}$ cell suppression and anergy are differentially regulated by proinflammatory cytokines produced by TLR-activated dendritic cells. J Immunol 173, 7249-7258 (2004).

88. den Haan, J.M., Kraal, G. \& Bevan, M.J. Cutting Edge: Lipopolysaccharide Induces IL10-Producing Regulatory CD4+ T Cells That Suppress the CD8+ T Cell Response. $J$ Immunol 178, 5429-5433 (2007).

89. Imanishi, T., et al. Cutting edge: TLR2 directly triggers Th1 effector functions. $J$ Imтипо 178, 6715-6719 (2007).

90. Marsland, B.J., et al. TLR ligands act directly upon T cells to restore proliferation in the absence of protein kinase C-theta signaling and promote autoimmune myocarditis. $J$ Imтипо 178, 3466-3473 (2007).

91. Melzer, N., Meuth, S.G. \& Wiendl, H. CD8+ T cells and neuronal damage: direct and collateral mechanisms of cytotoxicity and impaired electrical excitability. FASEB $J \mathbf{2 3}$, 3659-3673 (2009).

92. Wong, C.K., et al. Activation profile of Toll-like receptors of peripheral blood lymphocytes in patients with systemic lupus erythematosus. Clin Exp Immunol 159, 11$22(2010)$.

93. Hornung, V., et al. Quantitative expression of toll-like receptor 1-10 mRNA in cellular subsets of human peripheral blood mononuclear cells and sensitivity to $\mathrm{CpG}$ oligodeoxynucleotides. J Immunol 168, 4531-4537 (2002).

94. Cottalorda, A., et al. TLR2 engagement on CD8 T cells lowers the threshold for optimal antigen-induced T cell activation. Eur J Immunol 36, 1684-1693 (2006).

95. Roark, C.L., Simonian, P.L., Fontenot, A.P., Born, W.K. \& O'Brien, R.L. gammadelta T cells: an important source of IL-17. Curr Opin Immunol 20, 353-357 (2008).

96. Caramalho, I., et al. Regulatory T cells selectively express toll-like receptors and are activated by lipopolysaccharide. J Exp Med 197, 403-411 (2003).

97. Crellin, N.K., et al. Human CD4+ T cells express TLR5 and its ligand flagellin enhances the suppressive capacity and expression of FOXP3 in CD4+CD25+ T regulatory cells. $J$ Immunol 175, 8051-8059 (2005).

98. Liu, H., Komai-Koma, M., Xu, D. \& Liew, F.Y. Toll-like receptor 2 signaling modulates the functions of CD4+ CD25+ regulatory T cells. Proc Natl Acad Sci U S A 103, 70487053 (2006). 
99. Round, J.L., et al. The Toll-like receptor 2 pathway establishes colonization by a commensal of the human microbiota. Science 332, 974-977 (2011).

100. Fort, M.M., et al. A synthetic TLR4 antagonist has anti-inflammatory effects in two murine models of inflammatory bowel disease. J Immunol 174, 6416-6423 (2005).

101. Ungaro, R., et al. A novel Toll-like receptor 4 antagonist antibody ameliorates inflammation but impairs mucosal healing in murine colitis. Am J Physiol Gastrointest Liver Physiol 296, G1167-1179 (2009).

102. Mullarkey, M., et al. Inhibition of endotoxin response by e5564, a novel Toll-like receptor 4-directed endotoxin antagonist. J Pharmacol Exp Ther 304, 1093-1102 (2003).

103. Arslan, F., et al. Myocardial ischemia/reperfusion injury is mediated by leukocytic tolllike receptor-2 and reduced by systemic administration of a novel anti-toll-like receptor-2 antibody. Circulation 121, 80-90 (2010).

104. Lazzaro, B.P. \& Rolff, J. Immunology. Danger, microbes, and homeostasis. Science 332, 43-44 (2011).

105. Leonardi, C.L., et al. Efficacy and safety of ustekinumab, a human interleukin-12/23 monoclonal antibody, in patients with psoriasis: 76-week results from a randomised, double-blind, placebo-controlled trial (PHOENIX 1). Lancet 371, 1665-1674 (2008).

106. Cua, D.J., et al. Interleukin-23 rather than interleukin-12 is the critical cytokine for autoimmune inflammation of the brain. Nature 421, 744-748 (2003).

107. Vermeire, K., et al. Accelerated collagen-induced arthritis in IFN-gamma receptordeficient mice. J Immunol 158, 5507-5513 (1997).

108. Krakowski, M. \& Owens, T. Interferon-gamma confers resistance to experimental allergic encephalomyelitis. Eur J Immunol 26, 1641-1646 (1996).

109. Komiyama, Y., et al. IL-17 plays an important role in the development of experimental autoimmune encephalomyelitis. J Immunol 177, 566-573 (2006).

110. Langrish, C.L., et al. IL-23 drives a pathogenic $\mathrm{T}$ cell population that induces autoimmune inflammation. J Exp Med 201, 233-240 (2005).

111. Murphy, C.A., et al. Divergent pro- and antiinflammatory roles for IL-23 and IL-12 in joint autoimmune inflammation. $J$ Exp Med 198, 1951-1957 (2003).

112. Kroenke, M.A., Carlson, T.J., Andjelkovic, A.V. \& Segal, B.M. IL-12- and IL-23modulated $\mathrm{T}$ cells induce distinct types of EAE based on histology, CNS chemokine profile, and response to cytokine inhibition. J Exp Med 205, 1535-1541 (2008).

113. Luger, D., et al. Either a Th17 or a Th1 effector response can drive autoimmunity: conditions of disease induction affect dominant effector category. $J \operatorname{Exp}$ Med 205, 799810 (2008).

114. Panitch, H.S., Hirsch, R.L., Haley, A.S. \& Johnson, K.P. Exacerbations of multiple sclerosis in patients treated with gamma interferon. Lancet 1, 893-895 (1987).

115. Masters, S.L., et al. Regulation of interleukin-1beta by interferon-gamma is species specific, limited by suppressor of cytokine signalling 1 and influences interleukin-17 production. EMBO Rep 11, 640-646 (2010).

116. Annunziato, F., et al. Phenotypic and functional features of human Th17 cells. J Exp Med 204, 1849-1861 (2007).

117. Fang, J., et al. The role of TLR2, TRL3, TRL4, and TRL9 signaling in the pathogenesis of autoimmune disease in a retinal autoimmunity model. Invest Ophthalmol Vis Sci 51, 3092-3099 (2010). 
118. Yoshino, S., Sasatomi, E. \& Ohsawa, M. Bacterial lipopolysaccharide acts as an adjuvant to induce autoimmune arthritis in mice. Immunology 99, 607-614 (2000). 


\section{Glossary}

Microbe-associated molecular patterns (MAMPs): Molecular patterns that are found in pathogens and commensal microorganisms, but not in mammalian cells.

Damage-associated molecular pattern molecules (DAMPs): Molecular patterns that are found in mammalian cells and are released as a result of cellular stress, cellular damage and nonphysiological cell death. DAMPs are released from the degraded stroma (for example, hyaluronate), from the nucleus (for example, high-mobility group box 1 protein, HMGB1) and from the cytosol (for example, ATP, uric acid, S100 calcium-binding proteins and heat-shock proteins). Such DAMPs are thought to elicit local inflammatory reactions

Pathogen-associated molecular patterns (PAMPs): Molecular patterns that are found in pathogens but not in mammalian cells. Examples include terminally mannosylated and polymannosylated compounds (which bind the mannose receptor) and various microbial components, such as bacterial lipopolysaccharide, hypomethylated DNA, flagellin and doublestranded RNA (all of which bind Toll-like receptors).

Alarmins: Endogenous molecules rapidly released by dead or dying host cells in response to injury or infection that activate innate immune responses, recruiting immune cells and activating dendritic cells to prime $\mathrm{T}$ cell responses. They are distinct from but elicit similar responses to those induced by exogenous pathogen-associated molecular patterns (PAMPs). Examples of alarmins include HMGB-1 and heat shock proteins that can bind to TLRs and other PRRs, but also inflammatory cytokines, such as IL-1 $\alpha$, released from necrotic cells.

Sterile inflammation: Inflammation, characterized by leucocyte recruitment, not involving infection but precipitated by activation of innate immune cells with endogenous mediators released from host cells (alarmins or danger-associated molecular patterns; DAMPs) following tissue injury and necrotic cell death.

NLRP3 inflammasome: Nucleotide-binding oligomerization domain, Leucine rich Repeat and Pyrin domain containing (NLRP) are a family of cytoplasmic proteins that can form high molecular weight signaling complexes, termed inflammasomes. The NLRP3 flammasome, contains the adaptor molecule, apoptosis-associated speck-like protein containing a CARD (ASC) and recruits pro-caspase-1, leading to its autocatalytic activation. Active caspase-1 catalyzes the cleavage of pro-IL-1 $\beta$, pro-IL-18 and pro-IL-33, resulting in the secretion of biologically active forms of these cytokines. The NLRP3 inflammasome mediates innate immune responses to exogenous bacteria, and environmental molecules, such as alum and asbestos and endogenous molecules, such as ATP and amyloid- $\beta$.

Lymphoid tissue inducer-like (LTi) cell: Innate lymphoid cells that constitutively express CD4 ROR $\gamma$ t, IL-23 receptor, aryl hydrocarbon receptor, and CCR6, but not CD3, NK1.1, CD11b, Gr1, CD11c or B220, found in the spleen and lamina propria and are an early source of IL-17 and IL22 in host defence and an important source of IL-22 in intestinal homeostasis. 


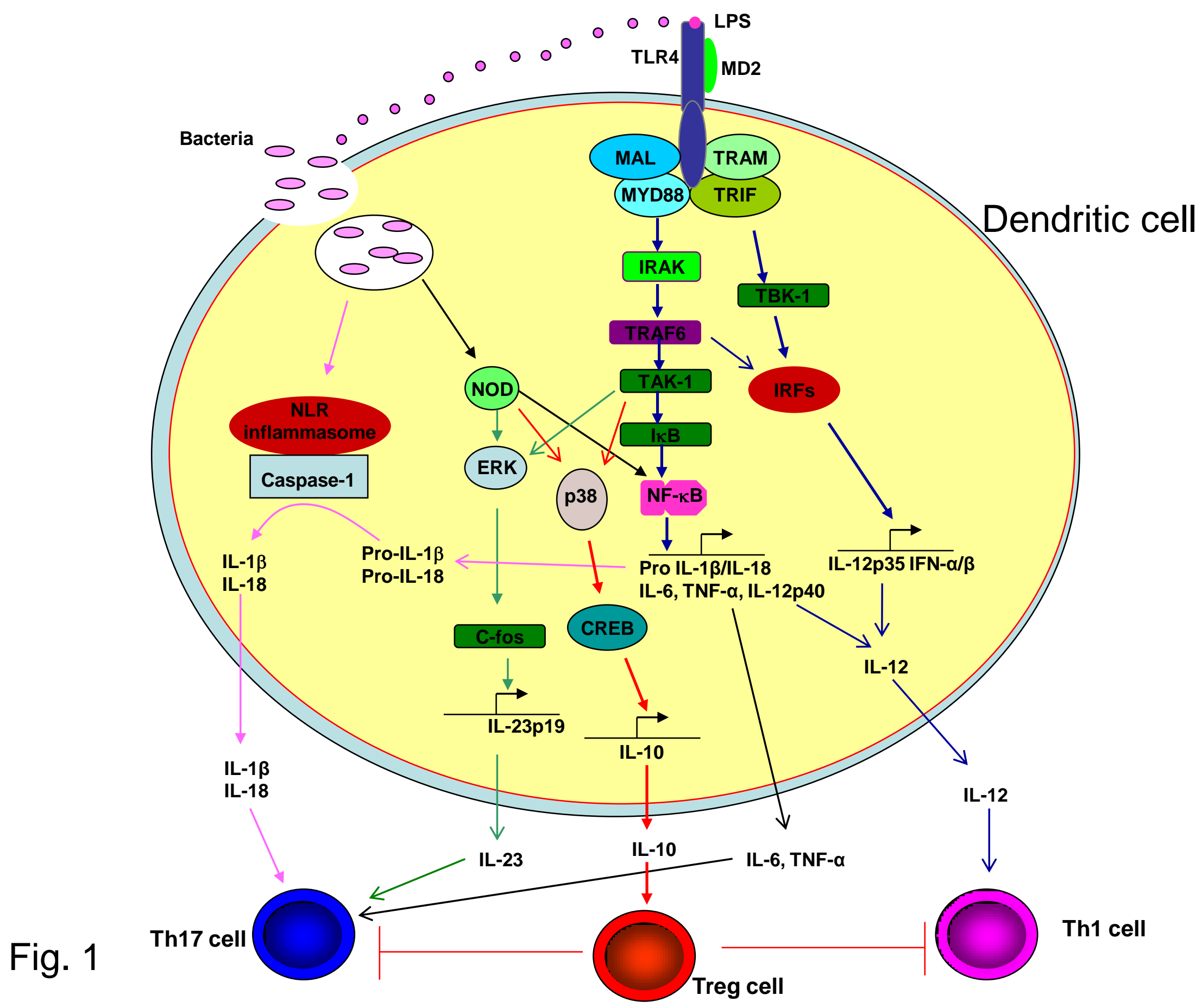




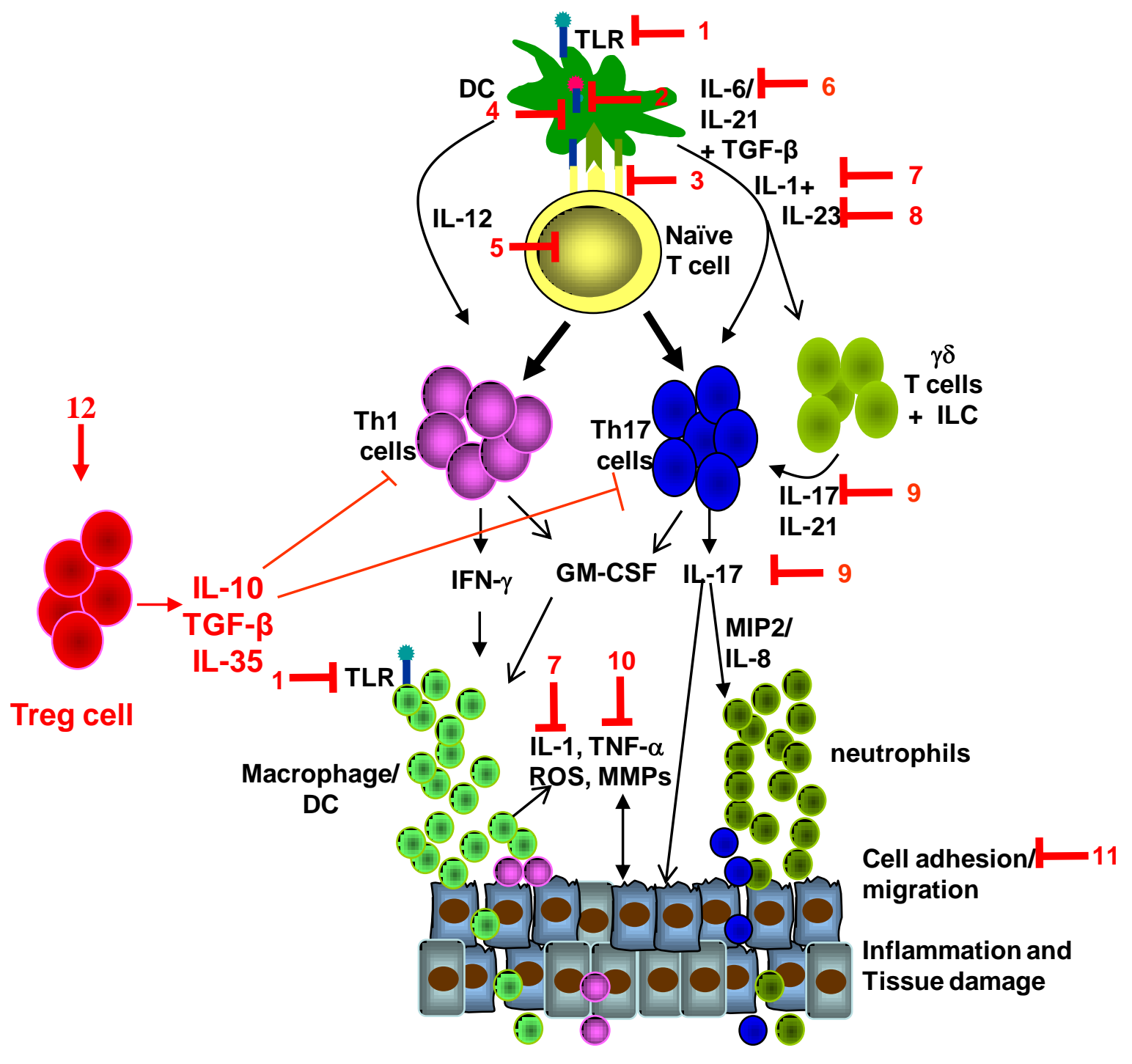

Fig. 2
Targets for biological response modifying drugs in autoimmune diseases

1. Antibodies/antagonists to TLRs (e.g. OPN305)

2. Inflammasome/ caspase-1 inhibitors (e.g. Pralnacasan, VX765)

3. Antibodies/Inhibitors of Ag presentation or $\mathrm{T}$ cell activation (e.g. CAMPATH-1, Abatacept)

4. MEK kinase inhibitors (e.g. ARRY438162)

5. JAK kinase inhibitors (e.g. CP690550, INCB018424)

6. Antibodies to IL-6/IL-6R (e.g. Tocilizumab)

7. Antibodies / antagonists to IL-1 $\beta$ (e.g. Anakinra, Rilonacept, Canakinumab, XOMA052)

8. Antibodies to IL-23p40/IL-12p19 (e.g. CNTO-1275

(ustekinumab), ABT-874, SCH 900222, STA-5326)

9. Antibodies / inhibitors of IL-17/IL17R (e.g. AIN457, LY2439821, AMG-827)

10. Antibodies / antagonists to TNF- $\alpha$ (e.g. Infliximab, Enberel, Humira)

11. Inhibitors of immune cell egress from lymph nodes or cell migration, adhesion or sequestration (e.g Tysabrai, Fingolimod)

12. $T$ reg cell induction or transfer (pre-clinical and phase I trials) 

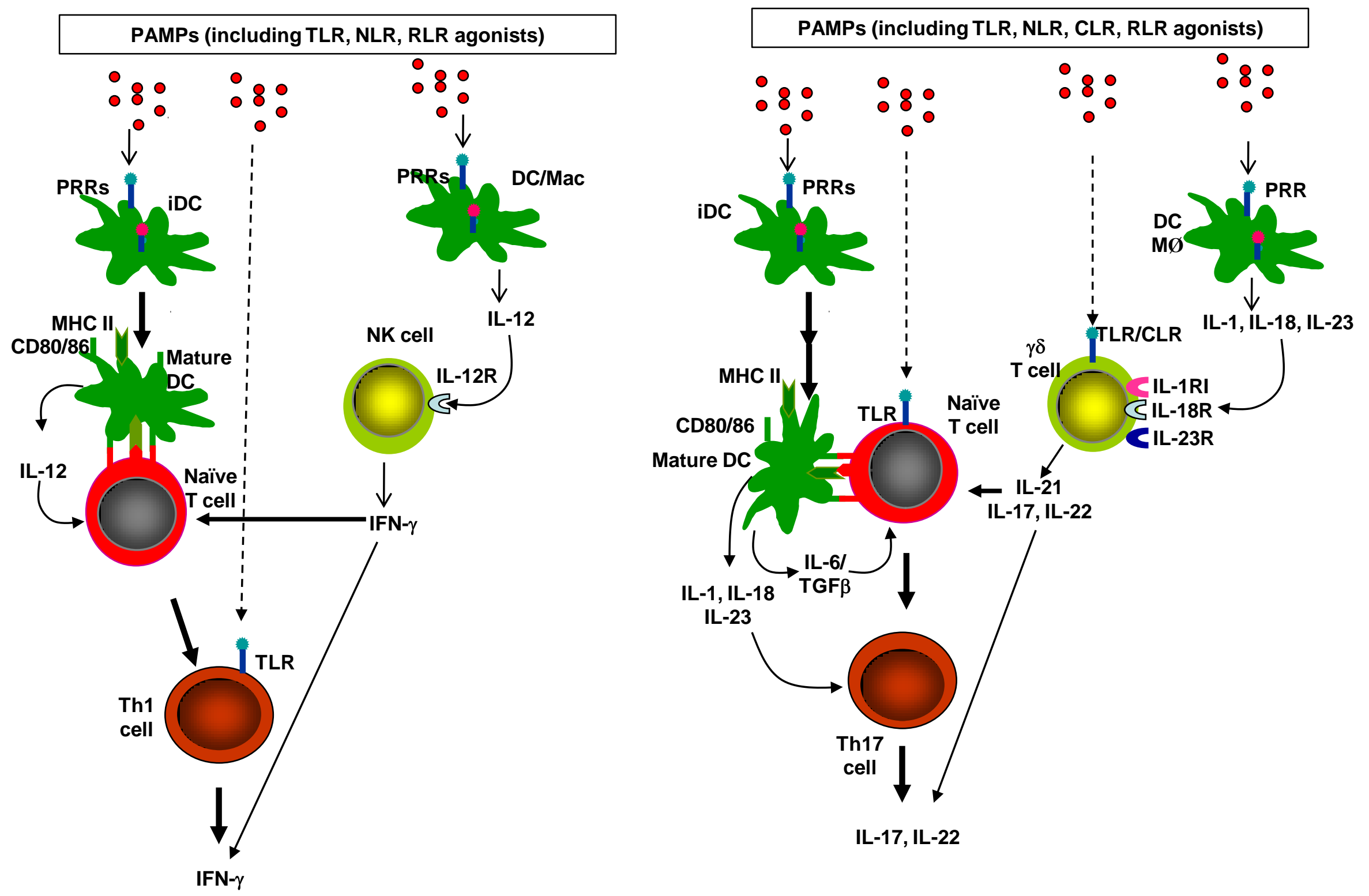

Fig. 3 
A. Infection/PAMP

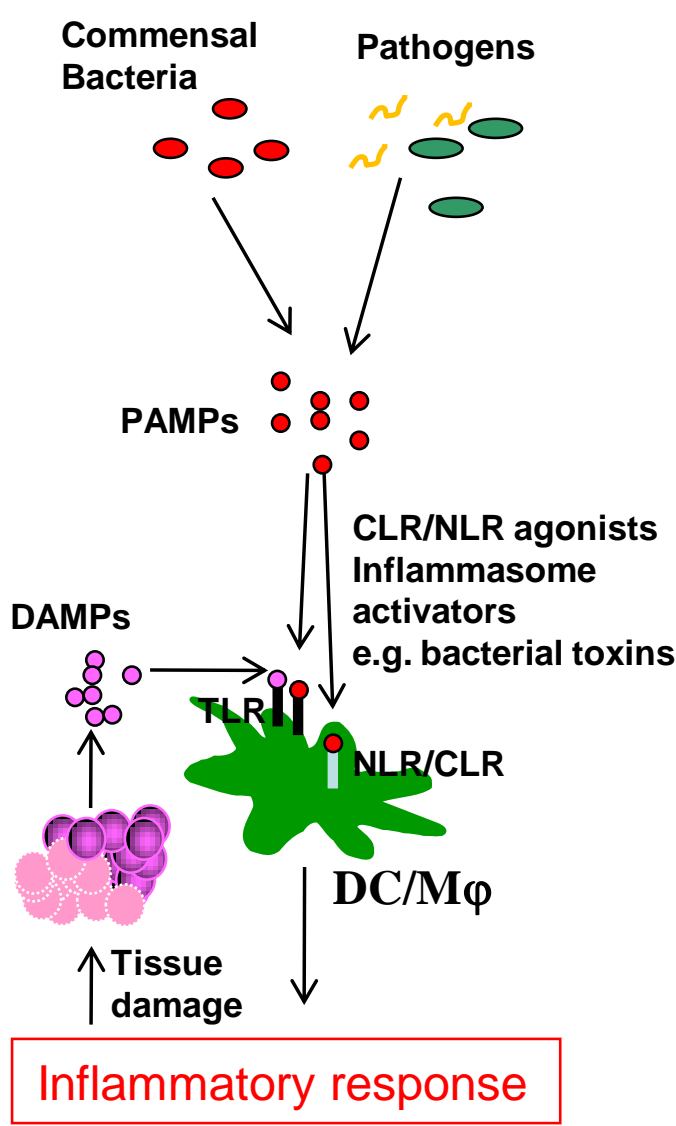

B. Damage/DAMP

Injury/tissue damage

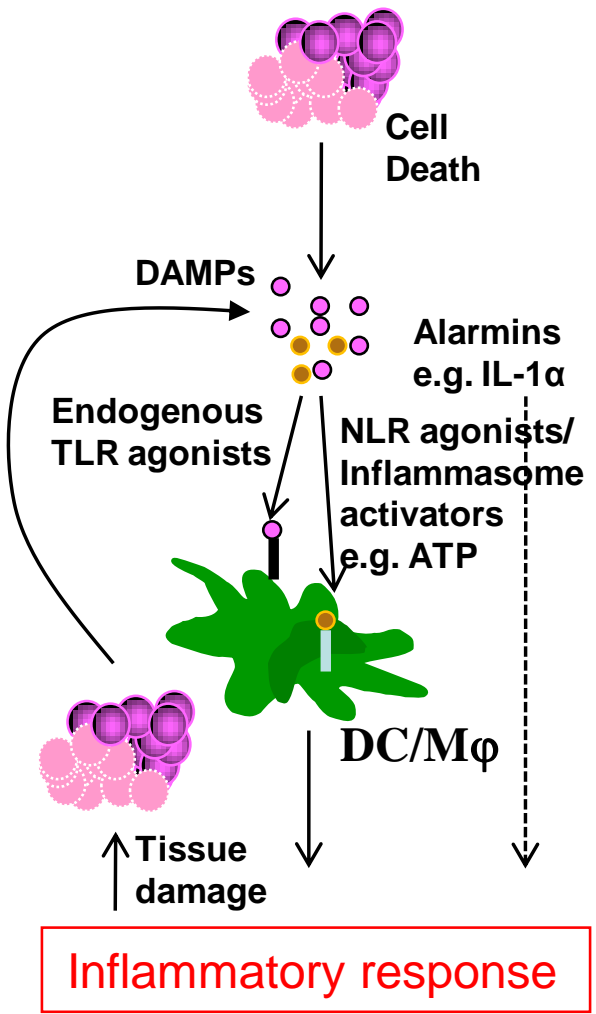

C. Microbe/MAMP and danger/DAMP
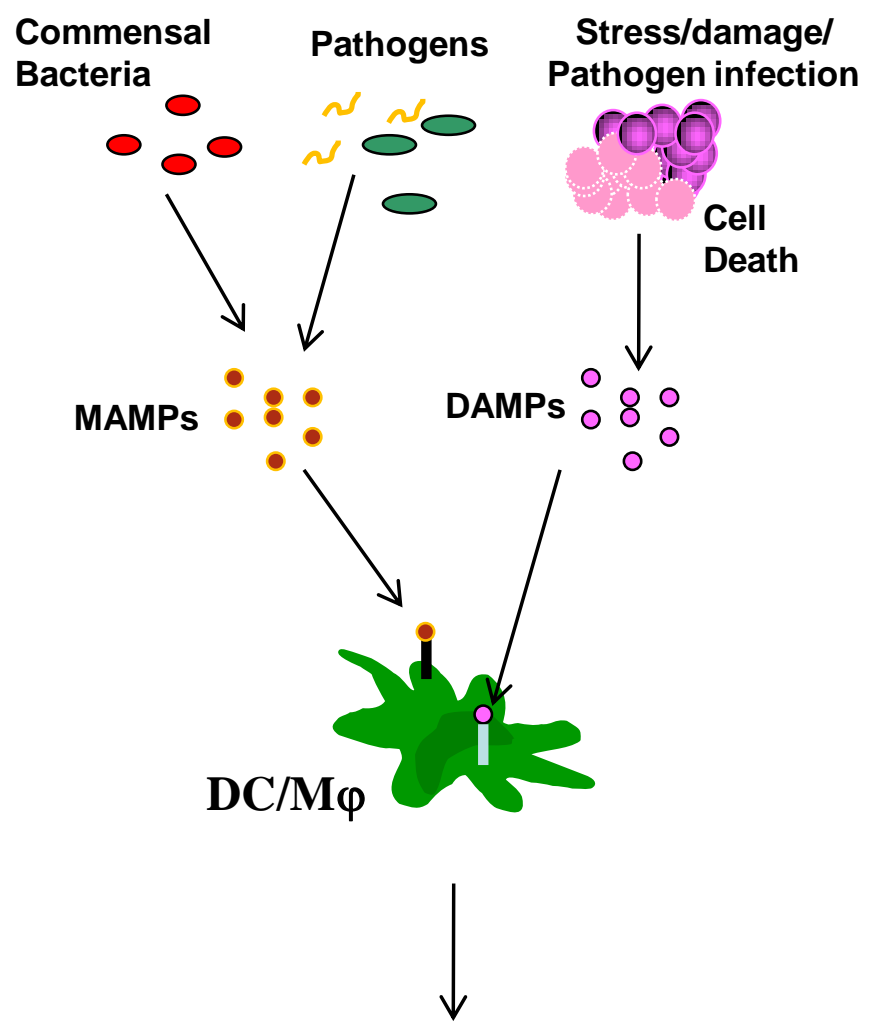

Inflammatory response

Fig. 4 